\title{
Poluição Eletromagnética: Telefonia Celular, Risco Sanitário-AMBIENTAL E a INCIDÊNCIA do Princípio da Precaução
}

\author{
ELETROMAGNETIC POLLUTION: CELLULAR TELEPHONY SYSTEM, \\ ENVIRONMENTAL AND SANITARY RISKS AND THE \\ PRINCIPLE OF PRECAUTION
}

Roberto Carlos Batista $\left.{ }^{\star}\right)$

\section{RESUMO}

A exposição humana a campos eletromagnéticos gerados por telefones celulares e estações rádios-base oferecem riscos à saúde pública e ao meio ambiente. Embora a ciência ainda não tenha dados e diagnósticos conclusivos, medidas de cautela vêm sendo adotadas em diversos países. $O$ caso é de aplicação do princípio da precaução para a proteção dos bens jurídicos envolvidos (ambiente e saúde); qualificados como direitos humanos e fundamentais.

\section{Palavras-chave}

Meio Ambiente; Poluição Eletromagnética; Princípio da Precaução; Saúde Pública; Telefonia Celular.

\section{ABSTRACT}

Human exposition to the electromagnetic fields generated by cellular telephones and radio stations offer risks to the public health and the environment. Although science has not conclusive diagnostics, countries have adop-

(*) Mestre em Direito e Estado, especialista em Direito Ambiental e Desenvolvimento Sustentável pela Universidade de Brasilia (UNB), doutorando em Direito pela Paris 1-Pathéon Sorbonne, integrante de seu Centre de Recherche en Droit des Sciences et Techniques, titular da $1^{\mathrm{a}}$ Promotoria de Defesa do Meio Ambiente e Patrimônio Cultural do Distrito Federal.E-mail:robertoob@mpdft.gov.br. Recebido em 7.8.06. Aprovado em 14.9.06. 
ting measures of caution. This is a situation that requires the application of the precaution principle in order to protect the legal rights (environmental and health), qualified as human rights.

\section{Key words}

Electromagnetic Pollution; Cellular Telephony; Public Health; Environment; Principle of Precaution.

\section{INTRODUÇÃO}

A tecnologia e sua sofisticação seduzem cada vez mais o consumidor com seus produtos e serviços; sempre associados à inovação, ao conforto, ao bem-estar do homem pós-moderno. No entanto, os riscos que representam quase nunca são revelados, apesar de ameaçarem, muitas vezes bens jurídicos ligados diretamente à vida como a saúde e o meio ambiente. O caso da telefonia celular é um exemplo marcante.

A partir dos anos 90 , assiste-se no mundo todo um incremento substancial na aquisição de telefones móveis. Estima-se que, atualmente, cerca de dois bilhões de pessoas façam uso desse serviço, ou seja, quase um terço da população mundial(1). E, dessa cifra, segundo divulgado recentemente pela Agência Nacional de Telecomunicações (ANATEL), só no Brasil, no final do mês de maio de 2006, o número de acessos ao serviço totalizou 92.377.336(2). As promoções e inúmeras propagandas acentuando as "vantagens" de um ou outro aparelho de pouco peso e dimensão, com determinada estética, com recursos de fotografia e filmagem, oferecidos por uma ou outra operadora, instigaram no público certa compulsão pela aquisição e uso de celulares. É comum a utilização de tais aparelhos até mesmo por crianças menores, com idade inferior a 12 anos.

Apesar da utilidade dos serviços que, por vezes, chega a poupar vidas, com a comunicação instantânea, efeitos deletérios devem ser avaliados, no âmbito do ambiente e da saúde pública e, como conseqüência, medidas assecuratórias hão de ser previstas em uma política pública integrada, visando sempre à qualidade de vida da população.

A preocupação da sociedade civil consciente, da comunidade científica, de alguns Estados e de organismos internacionais vem sendo recentemente acentuada, diante da probabilidade de poluição eletromagnética ensejada pelo

(1) Segundo informação divulgada em matéria publicada pela Folha on line, disponivel em $<<$ http:// www1.folha.uol.com.br/folha/informatica/ult124u18986.shtml >. Acesso em 11.07.06.

(2) Disponivel em: http://www.anatel.gov.br/biblioteca/releases/2006/release_19_06_2006mm.pdf. Acesso em 11.07.06. 
mecanismo de funcionamento dos celulares, bem como pelas chamadas estações rádios-base (ERBs), um conjunto de antenas transmissoras e receptoras estruturadas em torres, postes, suportes que recebem e emitem sinais através de ondas do tipo eletromagnética, para efetuar a comunicação dos aparelhos celulares. Seu funcionamento dá-se através de radiofreqüência ou microondas, que produzem uma radiação não-ionizante, ou seja, aquela que não chega a provocar lesões ou desintegração físicas, pois não tem a capacidade de romper com as moléculas de ADN, mas ensejam aumento de temperatura, podendo afetar a saúde humana. $\mathrm{Na}$ faixa de tais radiações, os campos eletromagnéticos (CEM), que variam de $\mathrm{OHz}$ a 300 $\mathrm{kHz}$, são considerados de baixa freqüência (como é o caso das linhas de transmissão de eletricidade); aqueles que variam de $300 \mathrm{kHz}$ a $300 \mathrm{GHz}$ são considerados de alta freqüência (como é o caso das ERBs).

No que se refere às ERBs, nota-se que a poluição eletromagnética manifesta-se tanto no ambiente natural, como no artificial. ${ }^{(3)} \mathrm{Em}$ face da maior oferta dos serviços de telefonia móvel e a sua privatização, o mercado competitivo busca oferecer um alcance mais amplo de transmissão, com qualidade superior. Logo, as empresas, a cada dia, multiplicam o número de equipamentos nas cidades, muitas vezes sem controle e de forma desordenada, ficando a população sujeita aos impactos e riscos muito graves. Embora ainda não cabalmente comprovada, a correlação com danos à saúde tem mobilizado as autoridades públicas e organismos internacionais a se ocupar da questão tão relevante.

A primeira parte desse trabalho apresentará a problemática da poluição eletromagnética oriunda das ERBs e telefones celulares (hoje objeto de tantos estudos e publicações). No primeiro momento, far-se-á um painel do tratamento do assunto na Europa, com ênfase na França. Já a segunda parte, apreciará um caso concreto oriundo da atuação do Ministério Público do Distrito Federal e Territórios, que deu origem a uma ação judicial (mandado de segurança coletivo, autos do Processo n. 2004002007932-3) interposta pela Associação Nacional das Operadoras de Celulares (ACEL) em face dos Secretários de Estado do Distrito Federal de Coordenação das Administrações Regionais e de Fiscalização das Atividades Urbanas, perante o Tribunal de Justiça daquela Unidade da Federação. Verificar-se-á também a incidência do princípio da precaução no caso examinado.

\section{O CAMPO ELETROMAGNÉTICO EA PREOCUPAÇÃO DO PÚBLICO}

As ondas eletromagnéticas existem desde o surgimento do universo. A sua forma mais comum é a luz; contudo, a exposição humana a tais ondas

(3) Conjunto das edificações (meio ambiente urbano) cujos padrões mínimos e harmonia são exigidos para um equilíbrio paisagístico e urbanístico, que garantirão à população bem-estar, melhores condições e qualidade de vida. 
incrementou-se substancialmente a partir da industrialização, com a demanda de eletricidade e seu consumo, com os avanços tecnológicos e as mudanças dos hábitos humanos. A exposição passou a acentuar-se no ambiente doméstico, por meio do uso de aparelhos eletrodomésticos (tais como televisores, rádios, fornos de microondas etc.), ou ainda no local de trabalho (computadores, impressoras, copiadoras etc.), com sofisticados produtos industriais e de telecomunicações (como celulares e telefones sem fio).

As iniciais inquietações do público decorreram das linhas de alta-tensão e sua interferência nas emissões de rádios-base e televisão, nos anos 60 e 70, envolvendo questões estéticas (na área de Arquitetura e Urbanismo) e de poluição sonora. Vieram então, já no início dos anos 70 , as primeiras reclamações de incômodos e transtornos sofridos por trabalhadores soviéticos em subestações elétricas, tendo sido iniciados estudos sobre o assunto, embora pouco difundidos ${ }^{(4)}$.

Em 1974, a Associação Internacional de Proteção a Radiações (IRPA) organizou um grupo de trabalho para o estudo da radiação não-ionizante. Em 1977, em congresso realizado em Paris, essa mesma associação transformou-se na Comissão Internacional de Radiações Não-lonizantes ${ }^{(5)}$, em inglês International Non-lonizing Radiation Commettee (ICNIRP), formalizando-se como uma organização não-governamental e passando a desempenhar um papel importante na fixação de padrões de segurança e estudos na área, recebendo o reconhecimento formal da Organização Mundial de Saúde (OMS) e da Organização Internacional do Trabalho (OIT).

Em 1979, um estudo relevante desenvolvido pelos pesquisadores americanos Ed Wertheimer e Nancy Leeper sobre a incidência de câncer infantil em Denver (Colorado, EUA), relacionada à exposição a campos eletromagnéticos, desencadeou outras centenas de pesquisas a respeito do tema e intensificou a preocupação do grande público, com os resultados sendo divulgados pela grande imprensa(6).

Desde então, estudos diversos empreendidos por equipes de profissionais multidisciplinares, ora por solicitação de empresas prestadoras de serviços de telefonia e de eletricidade, ora pelo governo ou por organismos internacionais (como a OMS), ou mesmo por exercício da investigação

(4) OMS. Bureau Régional pour l'Europe. Les champs életromagnétiques. Compenhague: OMS/Europe, 1999, p. e4 (collection de brochures Collectivités locales, environnement et santé, n. 32)

(5) DRUMOND, Ivens; FRANCO NETTO, Guilherme; FERMMER. André.CEM: Campos eletromagnéticos: aspectos legais e impactos sobre a saúde: perspectivas e sugestões. In Escola Superior do Ministério Público de São Paulo; Imprensa Oficial Estado de São Paulo. Poluição eletromagnética: saúde pública, meio ambiente, consumidor, cidadania: impacto das radiações das antenas e dos aparelhos celulares. Caderno Jur. São Paulo, v. 6, n. 2, p. 229, abr./ jun. 2004.

(6) Embora contestadas as conclusões dos estudos americanos à época, em junho de 2001, o Centro Internacional de Pesquisa sobre o Câncer as confirmou e considerou os campos eletromagnéticos como "cancerígenos possíveis ao homem" (categoria 2B), sob a base de estudos epidemiológicos com crianças. (CICOLELLA, André; BROWAEYS, Dorothé Benoit. Alertes santé. Paris: Fayard, 2005, p.132) 
científica, vêm alcançando resultados no mínimo preocupantes, pois não garantem a segurança da proteção à saúde e ao ambiente.

Os resultados dos estudos e os relatos de pessoas que fizeram uso prolongado e intenso da telefonia celular ou residem próximas de redes de eletricidade de alta-tensão de ou de ERBs, bem como as ações judiciais indenizatórias, sobretudo nos Estados Unidos, atribuindo o aparecimento de câncer à poluição eletromagnética, despertaram no público uma certa inquietação e, em determinados países, a adoção de algumas medidas em caráter preventivo, de natureza legal ou regulamentar.

\section{ESTUDOS DESENVOLVIDOS SOBRE OS EFEITOS DA RADIAÇÃO E POSSÍVEIS DANOS A SAÚDE}

A maioria dos estudos realizados sobre o tema até então se concentraram sobre os chamados efeitos térmicos, ou seja, aqueles decorrentes do aquecimento direto dos tecidos biológicos, que absorveram a energia eletromagnética de alguma fonte em um meio dissipativo ou com perdas. ${ }^{(7)}$ Os efeitos térmicos são resultado da ação de ondas eletromagnéticas sobre moléculas, como as de água, que se acham presentes nos tecidos humanos e são friccionadas internamente na freqüência da fonte incidente, ensejando o aquecimento do tecido atingido. A intensidade do aquecimento variará conforme a natureza dos tecidos alvejados pelas ondas e a densidade de água que eles possuem, além, obviamente, da freqüência da onda eletromagnética operante(8). Suspeita-se que conseqüências graves à saúde humana podem aparecer como cataratas, afetação do sistema nervoso central, do sistema cardiovascular, do sistema de regulação térmica do organismo e do sistema auditivo(9).

Já os chamados efeitos não térmicos "são, por exemplo, efeitos bioquímicos ou eletrofísicos causados diretamente pelos campos eletromagnéticos induzidos, e não indiretamente por um aumento localizado ou distribuído de temperatura."(10) Embora tais efeitos ainda não tenham sido comprovados

(7) FERNÁNDEZ, CC; SALLES , A. A. de. O impacto das radiações não-ionizantess da telefonia móvel e o princípio da precaução. In Escola Superior do Ministério Público de São Paulo; Imprensa Oficial Estado de São Paulo. Poluição eletromagnética: saúde pública, meio ambiente, consumidor, cidadania: impacto das radiaçóes das antenas e dos aparelhos celulares. Caderno Jur. SP, v. 6, n. 2, p. 19, abr./ jun. 2004.

(8) SANTINI, Roger. Téléphone mobiles cellulaires et station relais: le risque pour la santé: arguments scientifiques et conseils pratiques. Paris: Marco Pietter Editeur, 1998 (Collection Résurgence), p. 127.

(9) GAUGIER, R. et al. Votre GSM, votre santé: on vous ment !: 150 pages pour rétablir la vérité: livre blanc des incidences du téléphone mobile et des antennes relais sur votre santé. Paris: Marco Pietter Editeur, 2003, p. 20 (Collection Résurgence).

(10) FERNÁNDEZ, CC; SALLES , A. A. de. O impacto das radiações não-ionizantes da telefonia móvel e o princípio da precaução. In Escola Superior do Ministério Público de São Paulo ; Imprensa Oficial Estado de São Paulo. Poluição eletromagnética: saúde pública, meio ambiente, consumidor, cidadania: impacto das radiaçōes das antenas e dos aparelhos celulares. Caderno Jur. SP, v. 6, n. 2, p. 22, abr./ jun. 2004. 
e exista dissonância de resultados, alguns estudos apontam para repercussões no sistema nervoso (problemas com o sono, cefaléias, perda de memória); no sistema endócrino (como tiroidismo); no sistema iconológico (mudanças linfáticas); no metabolismo e em fatores hereditários, além de patologias graves e alterações nas membranas celulares, no que se refere ao movimento de entrada e saída de moléculas essenciais como de cálcio, sódio e potássio(11).

Inúmeros são os estudos já desenvolvidos, e em realização, que examinam a possibilidade da ação dos campos eletromagnéticos resultar em danos biológicos e à saúde humana, máxime com o uso de telefones celulares e a exposição da população a fontes irradiadoras como as estações rádios-base a se multiplicarem de maneira extraordinária a cada dia nas paisagens urbanas. As maiores preocupações dizem respeito ao aparecimento de tumores e, sobretudo, tumores cerebrais. A título exemplificativo, pode-se citar algumas pesquisas empreendidas e publicadas, embora grande parte delas contestadas, sobre os impactos da exposição a campos eletromagnéticos.

No final da década de 90 , quatro grupos de pesquisa investigaram os possíveis efeitos cancerígenos da exposição em referência na incidência de tumores de mama induzidos por substâncias químicas, obtendo resultados contraditórios. A análise do conjunto de dados apontou para uma viável relação entre a incidência dos tumores e o fluxo de densidade magnética

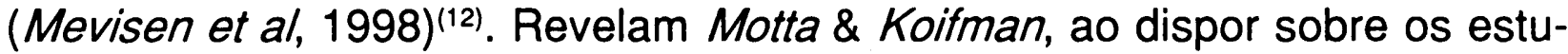
dos que "em grupos de camundongos submetidos a doses baixas de um agente iniciador (campos de baixa freqüência), foi observado um aumento estatisticamente significativo da incidência de tumores mamários, após a exposição a campos magnéticos de 10 1/4t, durante 27 semanas (ThunBattersby et al, 1999)"(13).

(11) FERNÁNDEZ, CC; SALLES , A. A. de. Op. cit. p. 22. GAUGIER, R. et al. Op. cit. p. 20. TEJO, Francisco de Assis Ferreira. Impacto dos campos eletromagnéticos ambientais sobre a saúde e a necessidade de adotar-se o princípio da precaução. In Escola Superior do Ministério Público de São Paulo; Imprensa Oficial Estado de São Paulo. Poluição eletromagnética: saúde pública, meio ambiente, consumidor, cidadania: impacto das radiaçōes das antenas e dos aparelhos celulares. Caderno Jur. SP, v. 6 , n. 2, p.180, abr./jun. 2004. LENTIN, Jean-Pierre. Ce sondes quituent, ces ondes qui soignent: téléphones portables, ordinateurs, micro-ondes, élétricité, magnétisme: quels dangers pour notre santé?Paris: Albin Michel, 2004, p.128-129. MATTOS \& KOIFMAN registram que: "Recentemente, foi publicado um estudo experimental, realizado com culturas de fibroblastos humanos, onde foi demonstrado um efeito genotóxico dos CEM, confimando achados de outros estudos similares, que vêm sendo realizados desde 1997, por diferentes pesquisadores (Ivancsits et al, 2003). Nesse experimento, foi observado que a exposição intermitente a CEM $(50 \mathrm{HZ} / 1,0000 \mathrm{~T})$ induzia quebras nas fitas de DNA, sendo essa alteração tempo-dependente e dose-dependente, e não relacionada a efeito térmico. Os resultados desses estudos abrem novas possibilidades e perspectivas na investigação dos efeitos biológicos dos CEM." (MATTOS, Inês; KOIFMAN, Sérgio. Campos eletromagnéticos e câncer: contribuição das ciências biológicas. In Escola Superior do Ministério Público de São Paulo; Imprensa Oficial Estado de São Paulo. Poluição eletromagnética: saúde pública, meio ambiente, consumidor, cidadania: impacto das radiações das antenas e dos aparelhos celulares.Caderno Jur. SP, v. 6, n. 2, p. 95, abr./ jun. 2004.

(12) Op. cit. p. 94.

(13) Idem. Ibidem. 
Ainda nos anos 90 , uma investigação científica empreendida pela equipe do Dr. Lennard Hardell, do Departamento de Oncologia do Centro Médico de Orebro (Suécia), por solicitação da OMS, chegara, em 1999, à constatação de que não se podia afirmar, categoricamente, que os casos de tumores benignos e malignos, diagnosticados entre 1994 e 1996 em pacientes que faziam uso de celular, estavam associados à utilização dos mencionados aparelhos de telefonia. A mesma equipe, ao dar prosseguimento às pesquisas em complementação aos estudos, publicou em 2000 a seguinte conclusão "o uso do telefone celular é um fator de risco de câncer de cérebro"(14).

Em outro estudo publicado em fevereiro de 2001, pela revista Epidemiology, sobre um câncer raro afetando o olho, após o exame de 118 casos e 475 acompanhamentos, acreditou-se em uma ligeira correlação com o uso de telefone celular ${ }^{(15)}$.

Constatações recentes dos eventuais efeitos dos celulares foram alcançadas por pesquisadores austríacos e suecos, após a análise de nove estudos epidemiológicos realizados nos Estados Unidos, Suécia, Dinamarca, Finlândia e Alemanha, sobre tumores cerebrais, câncer de glândulas salivares, melanomas intraoculares etc. Ao criticarem as deficiências metodológicas na totalidade dos estudos verificados e a probabilidade de erros, concluem que "todos os estudos trazem um risco de câncer associado à utilização de celular, os riscos relativos variam entre 1,3 e 4,6; o risco mais elevado seria o do neurinoma do acústico $(3,5)$ e o melanoma da úvea [úvea é uma membrana do olho] $(4,2)$. O risco de câncer aumentou com o aumento da latência e da duração de sua utilização"(16). A própria OMS, em brochura especializada, ao dizer que os campos eletromagnéticos não podem por si mesmos provocar câncer, admite "certos estudos em laboratório indicam que eles podem contribuir com o desenvolvimento de tumores de pele induzidos quimicamente em animais. Outras pesquisas dedicam-se aos mecanismos possíveis de desenvolvimento"(17). No mesmo sentido, autores que negam o liame do efeito cancerígeno a radiações não-ionizantes, ratificam que elas podem desempenhar um papel de desencadeadores de células cancerígenas já formadas ${ }^{(18)}$.

(14) "L'usage du telephone portable est un facteur de risque pour le cancer du cerveau." .Apud. LENTIN, Jean-Pierre. Ce sondes qui tuent, ces ondes qui soignent: téléphones portables, ordinateurs, microondes, élétricité, magnétisme: quels dangers pour notre santé?Paris: Albin Michel, 2004, p. 134.

(15) LENTIN, Jean-Pierre. Op. cit., p. 140.

(16) "toutes les études trouvent un risque de cancer associé à l'utilisation du portable, les risques relatifs variant entre 1,3 et 4,6 , le risque le plus élevé étant pour le neurinome acoustique $(3,5)$ et le mélanome uvéal [uvée est une tunique de l'oeil] $(4,2)$. Le risque de cancer est augmenté avec l'aumengtation de la latence et de la durée d'utilisation." ApudCICOLELLA, André; BROWAEYS, Dorothé Benoit. Alertes santé. Paris: Fayard, 2005, p. 133.

(17) OMS. Op. cit.p. e 8.

(18) GUÉNEL, Pascal et al. Rayonnement non ionisants. In GUERIN, Michel et al. Environnement et santé publique: fondements et pratiques. Canadá: Editions TEC \& DOC/Edisem, 2003, p. 451. 
Quatro profissionais não integrantes do grupo de cientistas instituído pela Agência Francesa de Segurança Sanitária Ambiental (AFSSA) para apresentar estudos sobre os possíveis efeitos ora em discussão, mas componentes de um Comitê Científico sobre Campos Eletromagnéticos (CSIFCEM), vêm criticando e contestando os relatórios da AFSSA (de 2001, 2002 e 2003) que concluem pela inexistência de provas contundentes de impactos maléficos à saúde humana da exposição a campos eletromagnéticos. São eles: Rochard Gautier, doutor em farmácia; Daniel Oberhausen, antigo aluno da Escola Normal Superior de Cachan (França) e professor agregado de física; Roger Santini, professsor-pesquisador no Instituto Nacional de Ciências Aplicadas (INSA) e membro da União Rádios-Base Científica Internacional e da Bioelectromagnetics Society americana. Em livro publicado em 2004, entre tantas considerações, citando estudos, fazem referências aos principais problemas suportados por moradores vizinhos de ERBs, a saber: alterações de humor, fadiga, ansiedade, déficits cognitivos a longo termo, depressão, suicídio(19). Revelam também que estudos que tiveram curso em diversos países entre 2000 e 2003 mostraram, a partir de questionários, que os moradores próximos de ERBs queixam-se de problemas assemelhados.

$\mathrm{Na}$ França, os resultados se encaminharam para: fadiga (dos moradores próximos até 300 metros de distância das ERBs); dores de cabeça, perturbações com o sono, sentimento de desconforto (até a distância de 200 metros); irritabilidade, problemas cardiovasculares, dificuldade de concentração (até a distância de 100 metros). Na Espanha, constatou-se que no grupo de pessoas pesquisadas, num raio de 150 a 250 metros de distância das antenas, as mais próximas foram as mais queixosas de incômodos como: dores de cabeça, perturbação de sono, perturbações cardíacas, dificuldades de concentração, irritabilidade, sentimento de desconforto, fadiga.

Um estudo austríaco dedicou-se a examinar a fadiga, a digestão e o aspecto cardiovascular, chegando à conclusão do aumento de problemas cardiovasculares e de velocidade da reação das pessoas submetidas a testes.

Um relatório governamental holandês apresentado em 2003, realizou pesquisas com pessoas submetidas a radiofreqüências do tipo torres de telefonia celular (GSM $900 \mathrm{MHz}$ - DCS $1.800 \mathrm{MHz}$ - UMTS $2100 \mathrm{MHz}$ ). Divididos em dois grupos: os chamados "eletros sensíveis" e os "não eletros sensiveis", os integrantes do estudo participaram de testes para averiguar os efeitos sobre funções cognitivas (memória, atenção visual etc.) e responderam a questionários que avaliaram os efeitos subjetivos. Constatou-se uma diferença entre as respostas dos dois grupos e uma diminuição global de bemestar (dos submetidos à UMTS); modificação de sentimento de hostilidade

(19) GAUGIER, R. et al. Votre GSM, votre santé: on vous ment l: 150 pages pur rétablir la vérité: livre blanc des incidences du téléphone mobile et des antennes relais sur votre santé. Paris: Marco Pietter Editeur, 2003, p. 41 (Collection Résurgence). 
(dos submetidos ao GSM); modificação de memorização (dos submetidos ao DSC e UMTS), modificação de atenção visual (dos submetidos à UMTS) e de vigilância (dos submetidos à GSM)(20).

Todos esses estudos são, no mínimo, polêmicos no meio científico, significando dizer não haver ainda prova, aceita pela comunidade acadêmica como incontestável, dos males que aportam os campos eletromagnéticos. Uma coisa, no entanto, é certa: apresentam riscos à saúde humana, como já assinalaram inúmeros trabalhos publicados ${ }^{(21)}$. Tal constatação basta para que medidas de precaução e estudos sejam aprofundados.

\section{MEDIDAS E POLÍTICAS GOVERNAMENTAIS}

Tendo em vista o espectro provocado por algumas conclusões de estudos, reclamações e questionamentos do público, muitos Estados soberanos e organismos internacionais têm procurado se precaver de providências, no sentido de assegurar maior tranqüilidade à população e também, ao menos no plano do discurso político, de proteger a saúde humana e o meio ambiente de eventuais impactos negativos.

No Japão, o Ministério do Trabalho e da Saúde encomendou pesquisas sobre os efeitos de campos eletromagnéticos, que estão sendo efetuadas pelo Instituto Nacional de Saúde Pública e pela Associação de Seguridade e Saúde Industrial, sendo que um Comitê está encarregado de apresentar os resultados até $2007^{(22)}$.

$\mathrm{Na}$ Coréia, em 2000, o Ministério da Informação e da Comunicação lançou um programa de pesquisa sobre campos eletromagnéticos, com pesquisas em campos eletromagnéticos, por um período de cinco anos. A segunda etapa já está sendo planejada.

$\mathrm{Na}$ Austrália, face ao número de reclamações do público sobre eventuais riscos sanitários provocados por telefones celulares, a Agência de Saxúde Nacional e de Pesquisa Médica realizou pesquisas, entre os anos de 1997 e

(20) Idem. Ibidem, p. 74-74

(21) Consoante assinalam CICOLELLA\& BROWAEYS, op. cit., p.132-133, em 2003, só no repertório Medline, com as palavras-chaves electromagnetic fields health, encontra-se 61 publicaçōes, e, em 2004 o número é de 43. Também livros polêmicos são freqüentemente lançados no mercado, como é o caso da obra de CARLO, George; SCHRAM, Martin. Téléphones portables: oui, ils sont dangereux: révelations d'un scientifique. Paris: Editions Carnot, 2001, 185 p. e recentemente do volumoso Combat pour un e idée : la pollution électromagnétique, publicado em 2005 pela France Europe Editions de autoria de J.Pierre Maschi.

(22) A informação das iniciativas dos governos do Japão e dos demais países a seguir narrados constam do relatório do grupo de especialistas contratados pela AFSSE e datado de abril de 2005, disponível in Association Française des Operateurs Móbiles (AFOM), Liens \& Documents. Disponivel em: http:// www.afom.fr/v3/FILE_DOWNLOAD.php?doc_ID=717\&mode=directOpen. Acesso em: 17.07.06. 
2000 , direcionadas para identificar eventuais riscos de tumores cerebrais. Entre 2001 e 2003, a mesma agência recebeu recursos suplementares para estudos sobre efeitos de exposição a longo prazo em relação à visão e audição. Findo esse período, o Ministério da Saúde autorizou em 2003 mais recursos financeiros e aprovou a criação de um centro especializado sobre o assunto.

No continente europeu, o Conselho da União Européia editou em 12 de julho de 1999 uma recomendação relativa à limitação de exposição do público a campos eletromagnéticos (de $\mathrm{OHz}$ a $300 \mathrm{GHz}$ ), publicada no Jornal Oficial das Comunidades Européias, na qual, entre outras medidas, estabeleceu-se que os países-membros da Comunidade deveriam: 1) adotar restrições e medidas referentes às fontes e utilização em caso de exposição ao público a campos eletromagnéticos por longa duração, com exceção das fontes usadas para fins médicos; quando os riscos e vantagens devem ser pesados, para se deixar de observar, se for o caso, as restrições de base; 2) avaliar riscos e vantagens para decidir se há ou não necessidade de agir, com a adoção de políticas para controlar a exposição do público aos campos eletromagnéticos; 3 ) fornecer informações apropriadas ao público, relativas aos impactos dos campos eletromagnéticos na saúde e medidas adotadas a respeito, para reforçar a proteção contra a exposição e riscos; 4) promover e avaliar pesquisas em programas nacionais de pesquisa, levando em consideração as recomendações em matéria de pesquisa comunitária e internacional, a partir do espectro mais largo de fontes, para melhorar os conhecimentos sobre o assunto. Vários programas de pesquisas estão em desenvolvimento na Suíça, Grã-Bretanha, Alemanha, Itália, Dinamarca e Finlândia.

$\mathrm{Na}$ França, a Lei de 9 de maio de 2001 criou a da Agence Française de Sécurité Sanitaire Environnementale (AFSSE), com a missão de "contribuir para assegurar a segurança sanitária no domínio do ambiental e avaliar os riscos sanitários ligados ao meio ambiente". Quatro relatórios oficiais sobre o assunto em discussão foram apresentados até então. O primeiro e bastante difundido documento ficou conhecido como Relatório Zmirou (por causa do diretor do grupo de trabalho: Dr. Denis Zmirou) e foi desenvolvido sob a responsabilidade do Ministério do Emprego e da Solidariedade - Direção Geral da Saúde.

Publicado em janeiro de 2001, chegou à conclusão de que no estado atual de conhecimento sobre efeitos térmicos e não térmicos, não se pode afirmar se há ameaças à saúde. Por outro lado, em resposta à questão referente à exclusão do risco sanitário, dizem os especialistas: "ainda que haja poucos argumentos científicos para sustentá-lo (o risco), a hipótese de efeitos sanitários não térmicos associados aos campos RF (radiofreqüência) de baixo nível não pode ser excluída, no estado atual de conhecimento" (grifos no original)(23). O segundo, produzido em 2002, consistiu em um relatório

(23) "... bien qu'il peu d'arguments scientifiques pour l'étayer, l'hipothése d'effets sanitaires non thermiques associés aux champs RF de faible niveau ne peut être exclue, en l'état actuel des connaissances." 
parlamentar sobre incidente eventual da telefonia móvel sobre a saúde, a cargo dos senadores Jean-Louis Lorrain et Daniel Raoul, do Office Parlamentaire d'Evaluation des Choix Scientifiques et Technologiques, cujas conclusões foram semelhantes às do relatório anterior.

O terceiro relatório, datado de março de 2003, assim como o quarto documento, de abril de 2005, foram produzidos diretamente pela AFSSE. Neste último, que se refere ao períodos de 2004 e 2005, os especialistas afirmam que "ainda não é possível concluir sobre os efeitos de campos eletromagnéticos ligados a ondas radioelétricas de telefonia móvel"(24). No entanto, mantêm a recomendação de medidas acautelatórias, tendo em vista que os impactos negativos não são categoricamente afastados, embora, entendam que não tenham sido comprovados, e reiteram a aplicação do princípio da precaução para os telefones móveis e o chamado de princípio da atenção, para as ERBs ${ }^{(25)}$.

No âmbito de regulamentação francesa, apareceram inúmeras normas específicas, visando à proteção do meio ambiente e da saúde humana, a saber: a) o Código dos Correios e Telecomunicações: Ordenação n. 2001670 , de 25 de julho de 2001; b) a Circular de 16 de outubro de 2001, relativa à implantação de antenas de reprodução de radiotelefonia móvel; c) o Decreto n. 2002-775, de 3 de maio de 2002, relativo aos valores-limites de exposição do público a campos eletromagnéticos; d) a Portaria de 8 de maio de 2002 fixando as especificações técnicas (nível do débito de absorção específica - DAS) aplicáveis aos equipamentos terminais elétricos; e) o Decreto de 8 de outubro de 2003 sobre a avaliação de conformidade dos equipamentos de telecomunicações e de equipamentos radioelétricos, seu funcionamento e utilização; f) a Portaria de 8 de outubro de 2003 sobre a informação dos consumidores concernente aos níveis de DAS e às precauções de uso; g) a Lei n. 2004-809, de 9 de agosto de 2004 relativa à saúde pública e h) a Lei n. 2004-669, de 9 de julho de 2004, relativa às comunicações eletrônicas e aos serviços de comunicação audiovisual(26).

(Ministère de l'Emploi et de la Solidarieté, Direction Générale de la Santé. Les téléphones mobiles, leurs stations de base et la santé: état des connaissances et recommandations. Paris: La Documentation Française, 2001, p. 288).

(24) " $n$ 'est pas encore possible de conclure sur les effets sanitaires des champs électromagnétiques liés aux ondes radioélectriques de la téléphonie mobile" AFOM. Téléphone mobile \& santé. Disponivel em "http://www.afom.fr/v3/FILE_DOWNLOAD.php?doc_ID=717\&mode=directOpen". Acesso em 17.07 .06 (25) A diferenciação se deu no Parecer da AFSSE de 2003 e será apreciada no item seguinte.

(26) A) Le Code des postes et télécommunications: ordonnance n. 2001-670 du 25 juillet 2001; b) la Circulaire du 16 octobre 2001 relative à l'implantation des antennes relais de radiotéléphonie mobile; c) le Décret du 3 mai 2002 relatif aux valeurs limites d'exposition du public aux champs électromagnétiques; d) l'arrêté du 8 octobre 2003 fixant les spécifications techniques (niveaux de DAS) applicables aux équipements terminaux radioélectriques; e) le Décret $n$. 2002-775 du 8 octobre 2003 sur l'évaluation de conformité des équipements terminaux de télécommunications et des équipements radioélectriques, leur mise en service et leur utilisation; f) Arrêté du 8 octobre 2003 sur l'information des consommateurs concernant les niveaux de DAS et les précautions d'usage; g) la Loi n.2004-809 du 9 août 2004 relative à la santé publique; h) la Loi n. 2004-669 du 9 juillet 2004 relative aux communications électroniques et aux services de communication audiovisuelle. 
Boa parte das medidas e normas vem sendo adotada em diversos países com os índices de exposição do público e recomendações da ICNIRP e da OMS. Esta última, em 1996, iniciou o Projeto Internacional de Campos Eletromagnéticos (Electromagnetic Fields - EMF), com a participação da ICNIRP, e diversos países, como a França, para avaliar os efeitos à saúde humana em vista da exposição a tais campos, prevendo-se sua conclusão, salvQ prorrogação para 2007. Tal projeto possui como objetivos, entre outros: 1) apresentar respostas internacionais coordenadas sobre os efeitos da mencionada exposição à saúde humana; 2) acessar a literatura científica e identificar falhas no conhecimento, as quais necessitem de pesquisas complementares para avaliar o risco à saúde; 3 ) incentivar um dado programa de pesquisa em conjunto com agências financiadoras; 4) facilitar o desenvolvimento de padrões internacionais para a exposição aos campos eletromagnéticos; 5) fornecer informações a autoridades nacionais, outras instituições, aos trabalhadores e ao público em geral sobre os perigos resultantes dos campos eletromagnéticos e das medidas mitigadoras necessárias ${ }^{(27)}$.

Há países que destoam das normas recomendadas pela OMS/ICNIRP, no que se refere ao índice de exposição humana tolerável aos campos eletromagnéticos, adotando índices de exposição maiores ou menores que aqueles instituídos pelas instituições citadas. Ocorre que os limites de exposição aos campos eletromagnéticos de baixa freqüência estabelecidos pela ICNIRP foram baseados em efeitos biológicos prejudiciais à saúde humana, identificados em estudos experimentais e associados à exposição aguda. Os experimentos não reproduzidos em outras pesquisas e as evidências de estudos epidemiológicos atuais não foram considerados.

De igual forma, não se levou em conta a exposição a longo prazo, como concluem MATTOS \& KOIFMAN, que acrescentam: "Os limites do ICNIRP também não consideram as evidências de estudos epidemiológicos que apontaram um maior risco de leucemia em crianças expostas a longo prazo a níveis acima de $0,1-0,3 \mathrm{~T}$. Conclui-se, assim, que embora esses limites, sem dúvida, ofereçam proteção contra certos efeitos nocivos diretos da exposição aguda, eles não são adequados a um critério abrangente de proteção ambiental."(28)

\section{O PRINCÍPIO DA PRECAUÇÃO}

No quadro de uma sociedade pós-moderna, situam-se os avanços tecnológicos e os perigos que representam em uma sociedade de risco,

(27) WHO. Electromagnetic Fields. Disponivel em "http://www.who.int/peh-emf/project/EMF_Project/en/ index 1.htm". Acesso em 17.07.06.

(28) MATTOS \& KOIFMAN. op. cit., p. 109-110. 
como denominou Ulrich Beck (1986)(29), ou em uma civilização de risco, como preferiu Patrick Lagadec (1981)(30). As inovações que encantam o consumidor e se tornam defasadas tão logo são lançadas - face à velocidade de outras novidades ou um detalhe sobressalente que, em seguida, supera o modelo anterior, tornando-o "defasado", além das "utilidades" que enunciam -, trazem, de maneira oculta, sérios riscos de reflexos negativos ao ambiente e à saúde ${ }^{(31)}$. $O$ caso dos campos eletromagnéticos que garantem o funcionamento da telefonia celular é um exemplo de tal realidade. Nesse contexto, aos poucos se construiu os contornos do conhecido princípio da precaução.

O princípio da precaução, conforme pontua a doutrina, foi concebido na Alemanha, nos anos 70 , sob a denominação de princípio da prevenção(32) (Vorsorgeprinzip). Partia de uma idéia de planejamento e engajamento seguro na luta contra a poluição, apesar das incertezas dos males causados ao meio ambiente ${ }^{(33)}$. A sua formulação e consolidação verificou-se no âmbito do Direito Internacional do meio ambiente, durante os anos 80 , não com a denominação hoje conhecida, mas com expressões assemelhadas ${ }^{(34)}$. Sua incorporação foi se fazendo paulatinamente, em documentos internacionais ${ }^{(35)}$.

(29) BECK, Ulrich. La societé du risqué: sur la voie d'une autre modernité. Trad. Laure Bernardi. Paris : Flammarion, 2003, $521 \mathrm{p}$.

(30) LAGADEC, Patrick. La civilization du risque:catastrophes technologiques et responsabilité sociale. Paris : Seuil, 1981 [ Collection "Science ouverture".

(31) Como adverte BECK: "Les risques qui sont acutellement au centre des préoccupations sont de plus en plus fréquemment des risques qui ne sont ni visible ni tangibles pur les personnes qui y sont exposées, des risques qui parfois même restent sans effet du vivant des personnes concernées, mais en ont pour leur descendence, des risques en tout état de cause qui ont besoin du recours aux "organes de protection" de ;a science - théorie, expériences, instruments de mesure - , pour pouvoir devenir "visibles", interprétable en trant que risques. Le paradignede ces dangers serait le cas des transformations génétiques liées à la radioativité, qui, parce qu'elles sont imperceptibles pour les personnes qu'elles touchent - comme le montre l'accident du réacteur d'Harrisburg - les livrent totalement au verdict, aux erreurs, aux controverses des experts, et ce au prix d'atroces souffrances nerveuses." BECK, Ulrich. Op. cit., p. 49

(32) Em nada se confunde com a definição do hoje conhecido como princípio da prevenção. Conforme ensina GROSSIEUX: "La "prévention" appele à une démarche rationelle, cohérente et prudente, qui repose sur une realité connue, un risque évalué. Fondée sur l'indentification scientifique des facteurs de risques, elle permet de réduire la probabilité des risques jamais parvenir à l'éradoqier d'où l'intérêt déterminant que présente à cet égard le développement de la connaissance." (GROSSIEUX, Patrick. Principe de précaution et sécurité sanitaire. Aix-en-Provence: Presses Universitaires d'Aix-Marseille, 2003, p.3132). KOURILSKY \& VINEY pontuam bem a distinção: "La distinction entre risque poetentiel et risque avéré fonde la distinction parallèle entre précaution et préventio. La précaution est relative à des risques potentiels et la préventions à de risques avérés." (KOURILSKY, Philipe ; VINEY, Geneviève. Rapport au Premier ministre:le principe de précaution. Paris: Editions Odile Jacob/La Documentation Française, 2000, p.18).

(33) GODARD, Olivier et al. Traité des nouveaux risques. Paris: Gallimard, 2002, p. 72

(34) GOSSEMENT, Arnaud. Le principe de précaution:essai sur l'incidence de l'incertitude scientifique sur la décision et la responsabilité publiques. Paris: L'Harmattan, 2003, p. 47 [ Coll. Logiques juridiques]. (35) A título de exemplificação pode-se citar: a Convenção quadro sobre a proteção da camada de ozônio , assinada em Viena, em 22 de março de 1985; que teve vigor a partir de 22 de setembro de 1988; o Protocolo de Montreal à citada Convenção, assinado em 16 de setembro de 1987, vigorando a partir de 
Na Declaração do Rio sobre Meio Ambiente e Desenvolvimento, resultado da Conferência das Nações Unidas sobre o tema em junho de 1992, o princípio foi expressamente previsto. Paralelamente, na Europa, no mesmo ano, foi incorporado no art. 130 do Tratado de Maastricht (que, posteriormente, transformou-se no art. 174 do Tratado de Amsterdam). Desde então, tem lastreado a legislação de diversos países.

Na França, ele foi introduzido pela Lei n. 95-101, de 1995 (Lei Barnier) e integrou-se ao Código Rural (art. L. 200-1), ao Código do Meio Ambiente (art. L. 110-1) e, em 2005, à Carta Ambiental (art. 5), ganhando o status de constitucional.

O conteúdo do princípio em exame acha-se bem expresso na Declaração do Rio: "De modo a proteger o meio ambiente, o princípio da precaução deve ser amplamente observado pelos Estados, de acordo com suas capacidades. Quando houver ameaça de danos sérios ou irreversíveis, a ausência de absoluta certeza científica não deve ser utilizada como razão para postergar medidas eficazes e economicamente viáveis para prevenir a degradação ambiental." (Princípio 15)

A aplicação do princípio da precaução tem se estendido freqüentemente no âmbito da saúde pública, em face de eventos marcantes como o do sangue contaminado na França (que se deu em 1985, com grande alarde em 1991)(36). Também se transpôs para o terreno da segurança alimentar, com o evento da "vaca louca" (Grã-Bretanha, 1996). Reconhecido pela Comunidade Européia (Comissão, Conselho de Ministros, Parlamento), nesse último episódio, recebeu a chancela da Corte Européia de Justiça, em 1998(37). $E$, desde então, sua aceitação tem sido mais tranqüila no setor ambientalsanitário e vem se firmando no setor de serviços.

No caso dos campos eletromagnéticos, no entanto, há quem o repulse, principalmente na França, tendo em vista, entre outros fatores, a diferenciação estatuída pela Agence Française de Sécurité Sanitaire Environnementale, em parecer sobre telefonia móvel, datado de 16 de abril de 2003.

Para a AFSSE, "o princípio da prevenção e o princípio da vulnerabilidade assim se traduzem: no caso de verificação de perigo, medidas deveriam ser adotadas para proteger, com prioridade, as pessoas vulneráveis. Já o princípio da precaução é concebido com as seguintes palavras: se a análise

\footnotetext{
1 de janeiro de 1989; a Declaração ministerial da segunda Conferência Internacional sobe a proteção do Mar do Norte, assinada em Londres, em 25 de novembro de 1987 (parágrafo VII); entre outros instrumentos internacionais.

(36) Segundo HERMITTE (2005), "na França, a cada crise emblemática, como resposta do poder público, cria-se uma agência governamental. No caso do ' sangue contaminado', foram criadas: a Agência Francesa de Sangue (1992) e a Agência Francesa de Medicamentos (1993)" (HERMITTE, Marie Angèle. Notas do seminário sobre risco (informação oral). École des hautes études en sciences sociales. Paris, 01.12.2005)

(37) GODARD et al. op. cit. p. 75.
} 
dos dados científicos disponíveis chegar a concluir pela existência de uma dúvida séria sobre a possibilidade de efeitos graves e irreversíveis, seria necessário adotar disposições visando reduzir esse risco potencial, mesmo se os fatos científicos não estiverem perfeitamente estabelecidos."(38) Finalmente, o princípio da atenção é elaborado: quando houver inquietação do público, mesmo sem dados científicos que as justifiquem, as preocupações sanitárias, se o fenômeno afetar muitas pessoas tornam-se "verdadeira questão de saúde pública à qual é importante responder por medidas adequadas, notadamente, escutando os casos de sofrimento e temores e lhes oferecendo respostas na medida do possível"(39). Conclui por adotar o princípio da precaução para os telefones celulares, diante da possibilidade de efeitos sanitários pela exposição aos campos eletromagnéticos. Já em relação às estações rádios-base optou-se pelo princípio da atenção, para atender à preocupação do público, por não se entender que não se dispõe de dados científicos atuais sobre riscos sanitários da exposição a campos eletromagnéticos gerados pelas ERBs ${ }^{(40)}$.

A decisão encerrada no mencionado relatório em relação às ERBs não atende o critério de proteção à saúde, ao ambiente e à vida humana. Ora, inúmeros são os trabalhos em que se assinalam os riscos à saúde decorrentes da exposição aos campos eletromagnéticos gerados por antenas de telefonia, como já se tratou no item 3. A própria França experimentou em 2000 episódio muito grave, como bem registra CICOLELLA \& BROWAEYS (2005, p.147): "A emergência de câncer em duas crianças nos arredores Oeste de Paris, em Saint-Cyr-l'École (Yvilines), focalizou o risco potencial de antenas de celular."(41) Não se está, de fato, lidando com uma anomalia imaginária, psicossomática, pois coloca em risco a integridade sanitária e a própria vida das pessoas. As diversas manifestações e reclamações de vizinhos de tais antenas com relatos de dores de cabeça, problemas de concentração, depressão, entre outras, não devem ser classificadas de "polimorfas" e "banais"(42), pois envolvem bens jurídicos muito valiosos, apesar da incerteza científica.

(38) "si l'analyse des données scientifiques disponibles devait conclure à l'existence d'un doute sérieux sur la possibilité d'effets graves et irréversibles, il serait nécessaire de prendre des dispositions visant à réduire ce risque potentiel, même si les faits scientifiques n'étaient pas parfaitement établis" AFOM. Liens \& Documents.Les réssources sur la "santé" en français. Document(s) de référence. Disponivel em: http:/ /www.afom.fr/v3/FILE_DOWNLOAD.php?doc_ID=279\&mode=directOpen" Acesso em 19.07.06

(39) "cela devient une véritable question de santé publique à laquelle il importe de répondre par des mesures adaptées, notamment en manifestant une écoute des souffrances et des craintes et en y apportant des réponses dans la mesure du possible." AFOM. Liens \& Documents.Les réssources sur la "santé" en français. Document(s) de référence. Disponivel em http://www.afom.fr/v3/ FILE_DOWNLOAD.php?doc_ID=279\&mode=directOpen" Acesso em 19.07.06

(40) Fonte indicada na nota 39.

(41) No mesmo trabalho, os autores fazem referência à pesquisa desenvolvida pela equipe de Gomes Peretta na Espanha: NAVARRO et al. The microwave syndrome: a preliminary study in Sapain. Eletromagnetic Medicine and Biology, 22, 2003, pp.161-169 ( ClOCOLELLA \& BROWEYS, op. cit., p. 147, nota 4).

(42) Adjetivos utilizados em obra coletiva pelo Dr. Zmirou-Navier, responsável pelo primeiro relatório oficial francês sobre o assunto de exposição a campos eletromagnéticos (NAVIER, Zmirou. Risques 
Com esteio no citado Relatório Zmirou, o Conselho de Estado, em 2002, firmou o entendimento de que a implantação de ERBs próximo a residências não autorizava a aplicação do princípio da precaução, por ausência de comprovados riscos à saúde ${ }^{(43)}$. Dessa maneira anulou os decretos municipais que proibiram tal instalação, como se deu no caso do ato expedido em 18 de dezembro de $2001^{(44)}$ pelo prefeito de Vallauris que, fundado no princípio da precaução, proibiu a implantação de equipamentos de radiotelefonia da sociedade SFR, a 300 metros de uma habitação. O Tribunal Administrativo de Nice, em 28 de março de $2002^{(45)}$, rejeitou o pedido de suspensão do ato do prefeito e, finalmente, o Conselho de Estado acoIheu o pedido, justificando o interesse da empresa de telefonia e reafirmando a ausência de provas de riscos sanitários ${ }^{(46)}$.

Por outro lado, a Carta do Meio Ambiente na França assegura como direito fundamental "viver em um meio ambiente equilibrado e favorável à saúde" (art. $\left.1^{\circ}\right)^{(47)}$, ao mesmo tempo em que expressamente acolhe o princípio da precaução, definindo-o nesses padrões: "Quando a realização de um prejuízo, ainda que incerto no estado de conhecimento científico, puder afetar de maneira grave e irreversível o meio ambiente, as autoridades competentes, por aplicação do princípio da precaução, hão de adotar medidas provisórias e proporcionais a fim de evitar a realização do prejuízo, assim como aplicar procedimento de avaliação dos riscos ocorrentes" (art. 5). ${ }^{(48)}$

émergents associés aux nouvelles technologies. Un cas d'ecole: les champs électromagnétiques associés à la téléphonie mobile. In BORDILLON, François; BRÜCKER, Gilles; TABUTEAU,Didier. Traité de santé publique. Paris: 2004, Flamarion, p. 110).

(43) KOSTREZEWSKI-PUGNAT resume a posição daquela Corte em relação ao princípio estudado: "Le Conseil d'État, dans six arrêts de principe prononcés le 22 août contre six ordonnances de juge des référés du tribunal adminstratif de Nice, rappelé les limites du périmètre d'intervention du maire en matière de santé publique. Les motivations du Conseil d'État confirment, in fine, les règles de mise en oeuvre du principe de précaution: la stricte proportionalité et nécessité dictée par un doute sérieux d'atteinte à la santé publique. En occurance, la Haute jurisdiction considère que ces condictions ne sont pas réunies et fait prévaloir les intérêts de l'opérateur de réseau 'en l'absence de risques sérieux prouvés pour la santé publique' " (KOSTREZEWSKI-PUGNAT, Valérie.Téléphoie mobile, environnement et santé: bilan d'une coexistence sous le conrole du juge. In: JCP-La Semaine Juridique Adminstration et Collectivités territoriales, n. 23, juin. 2003, p. 736).

(44) Embora no processo correspondente conste o ano como 2001, por erro, como explica DELHOSTE em nota a artigo que publicou a respeito. (DELHOSTE, Marie-France. Radiotéléphonie mobile et principe de précaution: la surprenante position du Conseil d'État. In: Expertise des système d'information, mars. 2003, p. 97, nota 1).

(45) ApudDELHOSTE, op. cit., p. 97.

(46) Diz a decisão "(...) qu'eu égard, d'une part, à l'intérêt qui s'attache à la couverture du territoire par le réseau de téléphonie mobile et, d'autre part, aux intérêts de la societé SFR, résultant notamment des autorisations qui lui on été délivrées et en l'absence de risques sérieux prouvés pour la santé publique, l'urgence justifie la suspension de la décision attaquée." (Arrêt Societé française du radiotéléphone (SFR), Conseil d'État, 22 août, 2002, page 106)

(47) "Art. 1're. - Chacun a le droit de vivre dans un environnement équilibré et favorable à sa santé."

(48) "Lorsque la réalisation d'un dommage, bien qu'incertaine en l'état des connaissances scientifiques, pourrait affecter de manière grave et irréversible l'environnement, les autorités publiques veillent, par application du principe de précaution, à l'adoption de mesures provisoires et proportionnées afin d'éviter la réalisation du dommage ainsi qu'à la mise en œuvre de procédures d'évaluation des risques encourus." 
Seu conteúdo já se fazia consagrar no Código do Meio Ambiente desde o ano de 1995 (art. L. 110-1, 1). No dispositivo daquele estatuto legal (art. L. 110-1, I), a saúde é contemplada dentro da concepção de desenvolvimento sustentável.

Por sua vez, entre os principais objetivos do 6ํㅜㄹ Programa de Ação Comunitária para o Meio Ambiente (2001-2010)(49), encontra-se o de "contribuir para atender um nível elevado de qualidade de vida e bem-estar social para os cidadãos, proporcionando-Ihes um meio ambiente no qual a poluição não tenha efeitos nocivos à saúde humana e ao meio ambiente, assim como encorajando um desenvolvimento urbano sustentável". O Programa Comunitário no Domínio da Saúde (2003-2008), ao prever ações sobre fatores determinantes da saúde e eleger as maiores prioridades, acentua: "ações de promoção de saúde acompanhadas de medidas bem como instrumentos específicos de redução e eliminação de riscos (item II, 3)."(50)

Todas essas disposições, associadas aos graves riscos sanitário-ambientais demonstrados em pesquisas científicas (embora não consideradas), a partir de constantes e semelhantes inquietações da população com relatos de repercussões à saúde, fundamentam a aplicação do princípio da precaução também para as ERBs. No momento da decisão política de escolher o nível de risco, o poder público poderia e deveria perfeitamente adotar o princípio da coerência, para dar um tratamento similar à situação dos telefones celulares.

\section{O TRATAMENTO DO TEMA NO BRASIL}

Diversamente do que se deu em muitos países europeus, no Brasil, o assunto só passou a ganhar evidência recentemente, com a privatização das companhias de telefonia e a explosão da oferta, no mercado competitivo, de telefones celulares, a partir do final dos anos 90 . A previsão da matéria no âmbito da legislação sequer foi aperfeiçoada. O assunto pode e deve ser tratado pela União, Estados e Municípios, segundo as normas constitucionais.

(49) "contribuer à atteindre un niveau élevé de qualité de la vie et de bien-être social pour les citoyens en leur procurant un environnement dans lequel la pollution n'a pas d'effets nuisibles sur la santé humaine et l'environnement ainsi qu'en encourageant un développement urbain durable " (art. 2, n. 2, da Decisão n. 1600/2002/CE, do Parlamento Europeu e do Conselho, de 22 de julho de 2002, Jornal Oficial L 242, de 9.10.2002).

(50) "(...)actions de promotion de la santé accompagnées de mesures ainsi que des instruments spécifiques de réduction et d'élimination des risques" (item II, 3). No item II, 3 do mesmo documento elege como prioridade também a necessidade de : " renforcer la capacité de réaction rapide et coordonnée aux menaces pour la santé telles que les menaces transfrontalières comme le $\mathrm{VIH}$, la nouvelle variante de la maladie de Creutzfeldt-Jakob et les affections liées à la pollution (ex. danger venant des rayonnements ionisants ou non ionisants et le bruit): dans ce contexte, le programme oeuvrera au développement, au renforcement et au soutien de l'exploitation et de l'interconnexion des mécanismes de surveillance, d'alerte précoce et de réaction rapide." (Decisão 1786/2002/CE do Parlamento Europeu e do Conselho, de 22 de setembro de 2002, Jornal Oficial L 271, de 9.10.2002). 


\subsection{Tratamento Legislativo}

O tema objeto de estudo envolve bens jurídicos distintos, sujeitos ao tratamento legislativo por diferentes Unidades da Federação Brasileira. Além de meio ambiente (incluso o aspecto paisagístico) e saúde, o assunto diz respeito a telecomunicações.

De acordo com a Constituição Federal Brasileira, a competência legislativa no que se refere à proteção da saúde e do meio ambiente pertence à União, Estados e Distrito Federal (art. 24, incisos VI, VII e XII, CF) de forma concorrente, ou seja, a União estabelece normas gerais e os Estados e o Distrito Federal normas específicas, podendo estes suprir a ausência de norma federal. Já no que concerne à telecomunicação e radiodifusão, a União Federal detém competência privativa para legislar (art. 22, IV, CF).

A competência material no que tange à saúde e ao ambiente, a seu turno, irá integrar a pauta comum da União, Estados e Municípios (art. 23, incisos II, III e VI, da CF). Aos Municípios ainda é autorizado legislar sobre assuntos de interesse local (art. $30, \mathrm{I}$ ), suplementar a legislação federal e estadual (art. 30, inciso II, CF) e , no plano material, se ocupar do ordenamento territorial e ocupação do solo (art. 30, VIII, CF).

Apesar de todas essas vias de ordenamento da matéria, lamentavelmente, ela vem sendo pouco manuseada no domínio de poluição eletromagnética.

Em nível federal, somente em 2 de julho de 2002 foi editada norma versando sobre os limites de exposição aos campos eletromagnéticos. Trata-se da Resolução n. 303 da ANATEL, a qual incorporou os limites estabelecidos na ICNIRP. Tal Resolução aprova e regulamenta a limitação da exposição aos campos elétricos, magnéticos e eletromagnéticos na faixa de radiofreqüências entre $9 \mathrm{kHz}$ e $300 \mathrm{GHz}$.

Criada pela Lei Geral de Telecomunicações (Lei n. 9.472 /97), a ANATEL recebeu, por intermédio do Decreto Federal n. 2.338, de 7 de outubro de 1997, "competência normativa pertinente às telecomunicações" (art. 16, V, anexo I). A constitucionalidade de tal competência é contestada por alguns autores, sob o argumento de que atentaria contra os princípios da separação dos poderes e da legalidade. "Além disso, as matérias que podem ser objeto de regulamentação são única e exclusivamente as que dizem respeito aos respectivos contratos de concessão, observados os parâmetros e princípios estabelecidos em lei. Não podem invadir matéria de competência do legislador." ${ }^{\prime(51)} \mathrm{Na}$ realidade, a Lei n. 10.683, de 28.05.03, em seu art. 27, inciso V, alíneas $a$ e $b$, atribui competência geral ao Ministério das Comunicações para formular a política nacional de telecomunicações e radiodifusão. Logo, a norma deveria ser originada no Parlamento Federal. Na prática, embora

(51) DI PIETRO, Maria Sylvia Zanella. Direito administrativo. 15. ed. São Paulo: Atlas, 2003, p. 407-408. 
haja projetos de lei federal(52) sobre o tema tratado na Resolução em exame, eles ainda não receberam a chancela parlamentar, restando, apenas, no cenário nacional, a mencionada Resolução.

No setor da saúde pública, de forma específica, a Portaria n. 3.214/78, de 8 de julho de 1978, do Ministério do Trabalho, que versa sobre a Segurança e Medicina do Trabalho, tratou de radiações não-ionizantes, no anexo $7 \mathrm{da}$ NR-15 sobre Atividades e Operações Insalubres. No entanto, deixou de estabelecer limites de tolerância à exposição ocupacional.

Também o Decreto Federal n. 3.048, de 6 de maio de 1999, que aprova - Regulamento da Previdência Social e dá outras providências, contempla, no Anexo II [Neoplasias (tumores)], do Grupo II, Cid-10, como agentes etiológicos e fatores de risco na atividade laboral, os campos eletromagnéticos.

No setor ambiental, no âmbito federal, só há normas gerais, perfeitamente aplicáveis à espécie; mas, sem a referência explícita a campos eletromagnéticos, por se tratar exatamente de uma preocupação recente. O Conselho Nacional do Meio Ambiente (CONAMA), que exerce função normativa, entretanto, criou um Grupo de Trabalho a fim de definir critérios de regulação das ERBs, mas ainda não editou nenhuma Resolução a respeito. De toda sorte, a Resolução CONAMA n. 1/86, de 23 de maio de 1986, há de ser empregada, uma vez que a poluição eletromagnética se amolda à hipótese de incidência do estatuto em referência, quando versa sobre impactos ambientais e afetação da saúde pública e do bem-estar da população(53).

Nas esferas estadual e municipal, muitas normas se produziram, tanto envolvendo posturas e ocupação do solo, aspectos sanitários e ambientais, como índices de exposição a ondas eletromagnéticas, licenciamento e padrões para instalação de estações rádios-base ${ }^{(54)}$.

\subsection{Políticas Públicas}

A intrincada correlação ambiente e saúde tem levado os poderes públicos a admitir as interpenetrações e a necessidade de um tratamento con-

(52) Pojetos de Lei ns. 2.576/2000 , 4.399/2001, 4.505/2001 , 4.587/2001, 5.241/2001, 5.843/2001; em trâmite no Congresso Nacional

(53) Diz a Resolução n. 01/86: "Art. 19. Para efeito desta Resolução, considera-se impacto ambiental qualquer alteração das propriedades físicas, químicas e biológicas do meio ambiente, causada por qualquer forma de matéria ou energia resultante das atividades humanas que, direta ou indiretamente, afetam: 1- a saúde, a segurança e o bem-estar da população."

(54) Pode-se citar, a título de exemplo: a Lei n. 10.995, de 2001, do Estado de São Paulo; a Lei Distrital n.3.446, de 23 de setembro de 2004; o Decreto Distrital n. 22.395, de 14 de dezembro de 2001; o Decreto Municipal de Campinas (SP) , de 26 de outubro de 1998 (o primeiro a dispor sobre a matéria) ; o Decreto Municipal de Porto Alegre (RS), de n. 12.153, de 13 de novembro de 1998; a Lei n. 8.706, de 15 de janeiro de 2001 (sobre a divulgação pelos fabricantes de telefonia celular, da Taxa de Absorção Específica -TAE) e a Lei Municipal n. 8.896 de 26 de abril de 2002; ambas de Porto Alegre; a Lei Municipal de Ubatuba(SP) n. 1.766 de 19 de novembro de 1998; o Decreto Municipal do Rio de Janeiro, n. 19.260 , de 8 de dezembro de 2000 ; entre outros textos legais. 
junto através de uma política pública integrada. Tal realidade está marcada indelevelmente na Lei n. 8.080, de 19 de setembro de 1990, que dispõe sobre as condições para a promoção, proteção e recuperação da saúde, a organização e o funcionamento dos serviços correspondentes, e dá outras providências. Esse instrumento normativo, em diversas passagens, faz a ligação da saúde com o ambiente, como se percebe, por exemplo: a) no seu art. $3^{\circ}$, parágrafo único, quando indica como condicionante sanitário o meio ambiente; b) no seu art. $6^{\circ}$, caput, quando prevê a atuação da vigilância sanitária no campo ambiental; c) no seu art. $6^{2}, \S 1^{9}$, quando, ao definir a vigilância sanitária, autoriza a atuação desse setor quando houver implicações sanitárias emanadas do meio ambiente; d) no seu art. 16, incisos II, IV, V, ao atribuir competência à direção nacional do Sistema Único de Saúde (logo, o Ministério da Saúde) para participar da formulação de políticas sanitárias com envolvimento ambiental (aí compreendido, o meio ambiente do trabalho).

No exercício desses objetivos, perante as implicações sanitárias e ambientais da exposição humana aos campos eletromagnéticos, a Fundação Nacional da Saúde (FUNASA), que integra a estrutura do Ministério da Saúde (MS) editou Portaria n. 220, de 20 de junho de 2002, à época em que the competia gerir o Sistema Nacional de Vigilância Ambiental em Saúde (SINVAS) ${ }^{(55)}$, criando grupos de trabalhos intersetoriais compostos por representantes dos setores governamentais, privados, universitários e sociedade civil.

Com o objetivo de subsidiar o posicionamento do MS, referente à exposição humana a campos eletromagnéticos provenientes de linhas de transmissão de alta-tensão para campos eletromagnéticos na faixa de 0 a $300 \mathrm{GHz}$. Posteriormente, dando prosseguimento aos trabalhos, com a nova estrutura regimental do Ministério da Saúde ${ }^{(56)}$, este, pela Portaria MS n. 677, de 4 de julho de 2003 constituiu um Grupo de Trabalho (GT) em campos eletromagnéticos, para avaliar e recomendar aspectos normativos ligados à exposição humana àqueles campos no espectro de 0 a $300 \mathrm{GHz}$. Ao final, o GT concluiu, entre outras coisas, ser recomendável a aplicação do princípio da precaução, bem como propôs a criação de uma Comissão Nacional de Bioeletromagnetismo.

Finalmente, pelo Decreto de 24 de agosto de 2005, o Presidente da República instituiu a Comissão Nacional de Bioeletromagnetismo, "com a finalidade de prestar apoio técnico e assessoramento na formulação de políticas públicas relacionadas à localização, à construção, à instalação, à ampliação, à modificação e à operação de equipamentos e aparelhos que geram campos eletromagnéticos não-ionizantes na faixa de freqüências entre 0 e $300 \mathrm{GHz}$, especialmente quanto aos aspectos referentes à exposição

(55) Competência que lhe foi conferida pelo Decreto n. 3.450, de 9 de maio de 2000.

(56) Tal reestruturação se deu através do Decreto n . 4.726, de 9 de junho de 2003. 
humana e ambiental" (art. $1^{9}$ ). Tal comissão interministerial será presidida pela Casa Civil da Presidência da República; mas, conta com a participação, entre outros, dos Ministérios da Saúde e do Meio Ambiente.

Ao que se nota, as políticas públicas no setor ainda são bastante incipientes em relação aos países europeus; todavia, começam a ser implementadas.

\subsection{Caso das Estaçóes Rádios-Base no Distrito Federal, o Trabalho do Ministério Público e o Posicionamento do Tribunal de Justiça do Distrito Federal e Territorios}

\subsubsection{Relato do fato}

Em razão da instalação desmedida das ERBs no Distrito Federal, sobretudo em Brasília, a população e parlamentares distritais começaram a apresentar representações junto ao Ministério Público do Distrito Federal e Territórios (MPDFT), perante a Promotoria de Defesa do Meio Ambiente e Patrimônio Cultural (PRODEMA) e a Promotoria de Defesa da Ordem Urbanística (PROURB). O conteúdo das representações dizia respeito a incômodos pessoais, paisagísticos e urbanísticos, somados à preocupação sanitária.

Através de uma atuação conjunta das duas unidades mencionadas, bem como com a participação das Promotorias de Defesa do Consumidor (PRODECOM) e da Educação (PROEDUC), o Ministério Público constatou que: a) a Administração Pública do Distrito Federal, a quem incumbiria licenciar a instalação (nos termos do o Decreto Distrital n. 22.395, de 14 de dezembro de 2001), após o necessário licenciamento na Agência Nacional de Energia Elétrica (ANEEL), não possuía o inventário dos equipamentos já em operação; b) muitas unidades haviam sido edificadas em locais muito próximos de residências, em pátio de escolas, nas cercanias de hospitais e de espaços ambientalmente protegidos (Unidades de Conservação), bem como na área compreendida em sítio tombado como patrimônio cultural da humanidade pela UNESCO; c) as instalações não eram precedidas de licenciamento ambiental.

Com o propósito de estabelecer uma discussão democrática sobre o assunto, ouvir a sociedade e os profissionais ligados à área, o Ministério Público do DF e Tocantins, em conjunto com a Associação dos Servidores da Vigilância Sanitária do DF, organizou, em Brasília, nos dias 25 e 26 de maio de 2004, o VII Seminário de Direito Sanitário, nele incluindo um painel sobre poluição eletromagnética e um grupo de trabalho aberto a todos os participantes, que elaboraram conclusões comuns.

Após audiências conjuntas com representantes das operadoras do setor em exercício no Distrito Federal e dos entes públicos federais e distritais afetos ao assunto, promoveu o levantamento do número de ERBs instaladas, 
por informação das próprias empresas de telefonia celular. Constatou-se que das 268 Estações identificadas, 168 achava-se na área tombada e mais de 30 em escolas (o que correspondia a $20 \%$ do total).

Em seguida, no propósito de proteger o meio ambiente (e nesse aspecto incluindo a paisagem) e a saúde pública (principalmente de pessoas mais vulneráveis como crianças e enfermos), em julho de 2004 expediu recomendações aos Secretários de Estado do Distrito Federal de fiscalização das atividades urbanas e de desenvolvimento urbano e de habitação, bem como a seis administradores regionais das áreas em que se encontravam as ERBs identificadas.

A recomendação, que é um instrumento de atuação extrajudicial do Parquet, conferido pelo art. 6º, inciso XX, da Lei Complementar n. 75/93(57), para a defesa de interesses e direitos da coletividade, no caso analisado, sugeria ao Poder Público, sob pena de responsabilização de seus agentes (art. 11, inciso II, Lei n. 8.429/92), em noventa dias, a adoçăo das seguintes providências: 1) "a retirada das ERBs situadas em escolas, hospitais, creches, asilos, unidades de conservação de proteção integral (art. $8^{\circ}$ da Lei Federal n. 9.985/2000) ou de Área de Relevante Interesse Ecológico, Jardim Zoológico e em propriedades de natureza privada no Distrito Federal"; 2) que não fosse autorizada novas ERBs no DF até que houvesse a regularização das já existentes.

Após a notificação das empresas de telefonia móvel pelos Secretários de Estado citados, para atender os termos das Recomendações do Ministério Público, bem como a disposições da Lei Distrital n. 3.446, publicada em 7 de outubro de 2004, a Associação Nacional das Operadoras Celulares (ACEL) impetrou mandado de segurança coletivo, perante o Tribunal de Justiça do Distrito Federal e Territórios (TJDFT) ${ }^{(58)}$, com o propósito de anular as determinações da Administração Pública, de modo a garantir às operadoras de celular no Distrito Federal a manutenção em funcionamento das ERBs implantadas. Fundamentou seu pedido alegando, entre outros argumentos, que o Distrito Federal não possui competência para legislar sobre telecomunicações e que houve violação dos princípios do contraditório, da ampla defesa e da proporcionalidade, antes da adoção da medida impugnada. A Desembargadora relatora proferiu decisão provisória (liminar) deferindo, até julgamento final, o pedido dos autores para suspender a determinação da Administração Pública. Em sua decisão, a Desembargadora dispôs: "(...) além de acarretar um pesado ônus econômico, implicará a imediata interrupção

(57) Diz o dispositivo: "Art. 6 ํㅡㄹ Compete ao Ministério Público da União: (...) XX - expedir recomendações, visando à melhoria dos serviços públicos e de relevância pública, bem como ao respeito, aos interesses, direitos e bens cuja defesa lhe cabe promover, fixando prazo razoável para a adoção das providências cabíveis."

(58) MSG n. 2004002007932-3. 
dos serviços de telefonia celular em boa parte do Distrito Federal, bem como comprometimento de sua qualidade nas demais."(59)

O julgamento da questão no Tribunal foi bastante polêmico, tendo em vista as divergências acerca de pontos relevantes e sobretudo o substancioso voto do Desembargador Nívio Gonçalves que, no julgamento, foi o primeiro a apreciar o mérito, trazendo à discussão aspectos como o princípio da precaução, a função constitucional do Ministério Público, os bens jurídicos afetados (ambiente, saúde, patrimônio histórico e paisagístico). O debate gerado, principalmente, a partir do voto citado, transitou em torno da competência legislativa do Distrito Federal e da aplicação do princípio da precaução e a proteção do direito à saúde e ao ambiente.

\subsubsection{Da competência Legislativa}

A grande controvérsia inaugural, durante toda a sessão de julgamento, girou em torno da competência do Distrito Federal de emitir normas dispondo sobre a instalação de torres de telefonia, pois muitos dos julgadores entendiam tratar-se de usurpação da competência federal. Ora, na realidade, a legislação objeto de discussão não versa sobre telecomunicações, que, como se viu (art. 22, IV, CF), é exclusiva da União Federal. O legislador distrital estabeleceu parâmetros de ocupação do solo e de proteção ao ambiente e saúde, o que, obviamente, insere-se dentro da competência legislativa do Distrito Federal, consoante já verificado no item anterior, por tratar-se de "direito legítimo no interesse da sociedade que representa", nas palavras do Desembargador Eduardo Oliveira, em seu voto (p. 70, do acórdão) ${ }^{(60)}$.

Inclusive, o Desembargador Nívio trouxe à colação o caso de uma ação direta de inconstitucionalidade em curso no Supremo Tribunal Federal, questionando o mesmo ponto, em face da lei do Estado de São Paulo (ADI n. $2.902 / S P)^{(61)}$. Segundo o parecer do Procurador Geral da República, as restrições daquela lei atacada referiam-se à proteção da saúde da população de São Paulo, contra os efeitos nocivos da radiação não-ionizante. Tal constatação também foi sentida pelo Advogado Geral da União, no mesmo caso,

(59) Às folhas 203-206 dos autos do processo.

(60) O Desembargador Nívio Gonçalves, de forma precisa, bem colocou no julgamento: “ (...) ao Distrito Federal, que, aliás, abarca as competências legislativas municipais e estaduais (art. 14 da Lei Orgânica do DF), é dado estabelecer normas destinadas, dentre outros, a garantir o fiel cumprimento do plano de ordenamento e ocupação territorial; proteger o patrimônio urbanístico, histórico, cultural, artístico, turístico, paisagístico, em grande parte, aliás, tombado; preservar e defender o meio ambiente, os recursos naturais; controlar a poluição, nas suas mais variadas formas de expressão; e, por conseguinte, garantir a saúde, o bem-estar e a qualidade de vida da comunidade." (fls. 31 e 32 do acórdão)

(61) A ação referida questiona a constitucionalidade dos arts. $3^{\circ}, 4^{\circ}$ e $5^{\circ}$ da Lei Estadual n. 10.995 daquela unidade da federação, de 21 de dezembro de 2001 e foi proposta pela Associação Brasileira das Prestadoras de Serviços de Telecomunicações Competitivas (TELCOMP). 
quando disse que o propósito da lei em evidência não era de concorrer com a União Federal na escala legislativa; mas sim de proteger a saúde(62).

Ainda que não houvesse a recomendação do Ministério Público, a Administração Pública tinha o dever de agir, com base na legislação vigente, pois estaria no uso de seu legítimo exercício de poder de polícia, atendendo ao princípio da legalidade e do bem comum.

\subsubsection{O Princípio da Precaução e o risco sanitário-ambiental}

No que se refere ao princípio da precaução, por um lado, é bastante positivo que tal preceito comece a comparecer em decisões de tribunais brasileiros, onde tem se mostrado ainda tão incipiente; diversamente do que ocorre nos países europeus, como se viu anteriormente ${ }^{(63)}$. Por outro lado, é lamentável que seja repudiado como fundamento, sob o argumento de que não há certeza de que a exposição a campos eletromagnéticos, como os gerados pelas ERBs, enseje danos à saúde humana. Ora, o conteúdo do princípio em epígrafe diz respeito à incerteza científica(64). Se os males ensejados fossem conhecidos, sem controvérsias científicas, não se configuraria o caso de aplicação do princípio da precaução e sim do princípio da prevenção. É a falta de constatação inequívoca no campo da ciência que deve mobilizar as autoridades a acautelar os danos, de modo a não agir após as repercussões negativas e não raramente catastófricas ${ }^{(65)}$.

(62) Citações constantes do voto do Des. Nivio Gonçalves às fls.35-44 do acórdão do TJDF ora em exame.

(63) Hermitte, ao dispor sobre a cultura do risco e suas transformações, explica como os valores foram sendo alterados, de modo a chegar-se no princípio da precaução, com o emblemático caso da "vaca louca": "À medida que os objetivos, inicialmente econômicos, de proteção à saúde e ao meio ambiente foram incorporados ao direito europeu, a Corte de Justiça das Comunidades européias revisou a hierarquia de seus valores. Assim, no caso da vaca louca, decidiu que 'o prejuízo econômico e social decorrente do embargo não poderia sobrepor-se aos graves danos em termos de saúde pública das populações. Nenhuma hesitação é permitida em razão do caráter mortífero da doença'." (HERMITTE, Marie Angèle. Os fundamentos jurídicos da sociedade do risco: uma análise de U. Beck. In: VARELLA, Marcelo (Org.). Governo dos riscos. Brasília. Rede Latino-Americana-Européia sobre governo dos riscos, 2005, p. 19)

(64) Como lembra a doutrina: "La précaution, quant à elle, s'applique vis-à-vis de situations qualitativement et quantitativement incertaines, vis-à-vis de risques hypotetiques, virtuels, inconsistents, non probabilisable, éventuellement plausibles mais non démontrés et dont la mécanisme demeure non identifié: il suffit qu'existent des éléments fondant une doute, si léger soit-il." (BESANCENOT, Jean-Pierre. Le principe de précaution devant les risques sanitaires. In LARCENEUX, André ; BOUTELET, Marguerite (Dir.). Le principe de précaution: débats et enjeux. Dijon: Éditions Universitaires de Dijon, 2005, p. 52 (Collection Sociétés).

(65) Nesse aspecto, adverte NOIVILLE : "Desse modo, o princípio busca um avanço em relação àquela atitude clássica - cujos efeitos ocorreram no caso da vaca louca oudo amianto - , que permite, pela simples razão do risco não haver sido confirmado por meio de uma prova científica, que se ignore a necessidade de certas advertências prévias e imediatas. O princípio implica uma contraposição a essa atitude clássica e convida a agir antes mesmo de se obter a provo do risco real." (NOIVILLE, Christine.Ciência, decisão, ação: três observações em torno do princípio da precaução. In: VARELLA, Marcelo (Org.). op. cit., p. 57) 
Com propriedade, em seu voto, o Desembargador Nívio Gonçalves lembrou que o princípio da precaução "já estava consagrado no Direito pátrio desde 1981, com o advento da Lei n. 6.938, que instituiu a Política Nacional do Meio Ambiente, por seu art. $4^{\circ}$, incs. I e VI, e içado a princípio constitucional em 1988, pelo inc. $V$ do art. 225". No mesmo sentido, asseverou o Desembargador Otávio Augusto: "No que concerne à questão envolvendo a possibilidade de malefícios à saúde humana em face da exposição a ondas transmitidas pelos equipamentos específicos de telecomunicações, essa dúvida se resolve pelo princípio mais coerente na espécie." Juntando-se à corrente minoritária, no julgamento, também o Des. Eduardo de Moraes Oliveira, assim se pronunciou: "Como disse o Desembargador Nívio Gonçalves, secundado pelo Desembargador Otávio Augusto, na dúvida, há de se decidir pela vida, resguardando, da melhor maneira possível, a sociedade, ou permitir a busca da certeza." (66)

Muito bem colocaram os três julgadores. Ora, o princípio em pauta tem seu alicerce na lei máxima do país. No setor da saúde, a própria Constituição o alberga, quando trata das ações e serviços públicos de saúde e elege como uma de suas diretrizes, o atendimento integral, com prioridade para as atividades preventivas (art.198, inciso II) e quando, discrimina, algumas atribuições do Sistema Único de Saúde (art. 200). De igual forma, o faz em relação ao ambiente, quando prevê, dentre outras medidas, o licenciamento ambiental e a exigência do Estudo Prévio de Impacto Ambiental (art. 225, $\$ 1^{\circ}$, IV). Logo, bem colocou o Desembargador Nívio quando disse: "(...) a observância desse princípio (o da precaução) pelo Poder Público é, inquestionavelmente, cogente, vinculando não apenas a atuação da Administração Pública, mas também o legislador e, principalmente, do Poder Judiciário."(67)

Ademais, o que está em risco é a saúde pública, a vida das pessoas e o meio ambiente que se categorizam como direitos humanos e fundamentais. No regime democrático de direito, bens assim qualificados constituem o cerne do sistema de proteção legal e se colocam em uma hierarquia superior aos demais valores e normas. No sistema constitucional brasileiro, eles vêm enunciados já no primeiro Título, quando se considera como um dos fundamentos da República Federativa do Brasil, a dignidade da pessoa humana (art. 1․, III, CF) e quando elege a prevalência dos direitos humanos como princípio norteador das relações internacionais (art. $4^{\circ}$, inciso II, CF). Em seguida, no Título II que se denomina Dos Deveres e Garantias Fundamentais, assegura-se a imediata aplicação das normas definidoras de direitos e garantias fundamentais (art. 50, $\S 1^{\circ}, \mathrm{CF}$ ) e prossegue: "Os direitos e garantias expressos nesta Constituição não excluem outros decorrentes do regime e dos princípios por ela adotados, ou dos tratados internacionais em que a República Federativa do Brasil seja parte." (art. 5오 § 2, CF) Mais adiante, diz

(66) Às páginas 47,66 e 71, respectivamente, do acórdão em análise.

(67) Às páginas 47 do acórdão em apreciação. 
ser vedada qualquer emenda constitucional que vise à abolição de direitos e garantias individuais (art. 60, $\S 4^{\circ}$, inciso IV, CF).

Dessa maneira, não há dúvida que em se tratando de bens jurídicos com a qualificação dos ora estudados, há de se adotar o máximo de medida protetora, dentro do razoável e segundo suspeitas científicas de violação(68), aplicando-se o princípio da precaução. Por isso, o Desembargador Otávio Augusto, em atenção aos valores humanos e fundamentais, pronunciou: "Ao me referir ao princípio, digo que ele está pautado em um brocardo muito conhecido de todos, qual seja, o in dubio pro societate, e jamais pró-indivíduo, pró-empresa, que, rigorosamente, na espécie, vê e tem seus olhos voltados à atividade econômico-financeira de um negócio que se revelou muito rentável no Brasil." Faz-se necessário ressaltar também que toda atividade econômica não se isenta de observar como princípio inserto no Título VII, Capítulo I, da Constituição Brasileira, que trata da Ordem Econômica e Financeira e mais especificamente dos Princípios Gerais da Atividade Econômica, a "defesa do meio ambiente, inclusive mediante tratamento diferenciado conforme o impacto ambiental dos produtos e serviços e de seus processos de elaboração e prestação" (art. 170, VI, CF).

\subsubsection{Aspecto Urbanístico e Cultural}

No que concerne à proteção do patrimônio cultural e da paisagem urbana, em que se coloca bem evidente o aspecto ambiental (ambiente cultural) ${ }^{(69)}$, no caso específico, diagnosticou-se uma quantidade enorme de ERBs na área tombada (168), a vulnerar a ordem urbanística e a ameaçar o patrimônio citado.

(68) Cumpre lembrar que, para a aplicação do princípio em debate, necessário se faz que haja ao menos alguma suspeita científica, com dados mínimos, como acontece na espécie estudada. Nesse sentido, é o magistério de Hermitte \& Dormont: "(...) dans les contextes d'incertitude, il est tout de même rare que l'on ne dispose d'aucune connaissance scientifique. On n'est pas dans le cadre d'une preuve achevée, de nature expérimentale et reproductible, certes. Mais on n'est pas non plus dans le vide, l'intuition ou la divination. Les scientifiques disposent de connaissances fragmentaires qui leur permettent de construire des faisceaux d'indices convergents. Cette notion familière au juriste qui est le plus souvent obligé de s'en contenter, est plus étrange pour le scientifique pour lequel elle traduit un inachèvement. Le domaine du principe de précaution est celui de la décision prise à partir de données scientifiques objectives quoiqu'elles ne constituent pas un savoir achevé et qu'elles ne soient pas susceptible de constituer des preuves selon les règles de la méthode expérimentale." (HERMITTE, Marie Angèle; DORMONT, Dominique. Proposition pur le principe de la précaution à la lumière de l'affaire de la vache folle. InKOURILSKY, Philippe; VINEY, Geneviève. Le principe de précaution. Paris: La Documentation Française, 2000, p. 349).

(69) Como bem se refere Marchesan, "Em nosso país, a paisagem se insere na noção unitária, sistêmica de meio ambiente. A Constituição Federal, a partir da exegese combinada nos arts. 182, caput, 216 e 225, reconhece a necessidade de proteção desse bem jurídico."(MARCHESAN, Ana Maria Moreira. As estações rádios-base-base de telefonia celular no contexto de uma sociedade de risco. In Escola Superior do Ministério Público de São Paulo; Imprensa Oficial Estado de São Paulo. Poluição eletromagnética: saúde pública, meio ambiente, consumidor, cidadania: impacto das radiações das antenas e dos apareIhos celulares. Caderno Jur. SP, v. 6, n. 2, p.147, abr./ jun. 2004.). A Lei n. 10.257, de 2001, a seu turno, em seu art. $2^{2}$, inciso XII, quando se refere a diretrizes de recuperação e preservação do meio ambiente, inclui o patrimônio histórico e cultural, como categorias de bem ambiental. 
Brasília, por suas características arquitetônicas e urbanísticas modernas, teve, desde o início, uma legislação que visou e ainda tenta preservar o seu patrimônio cultural. Assim, o art. 38, da Lei n. 3.751, de 13 de abril de 1960 (conhecida como Lei Santiago Dantas), já previa que qualquer alteração na sua área mais importante (o Plano-Piloto) só se operasse através de lei federal. O Decreto n. 10.829, de 4 de outubro de 1987, veio regulamentar aquele dispositivo e definiu as características fundamentais da cidade, a serem resguardadas em quatro escalas: monumental, residencial, gregária e bucólica. Em 7 de março de 1987, por seus valores arquitetônicos, fora o primeiro núcleo urbano contemporâneo a ser incluído na lista de bens de valor universal pelo Comitê do Patrimônio Mundial, Cultural e Natural da UNESCO. Em 14 de março de 1990, o então Instituto Brasileiro de Patrimônio Cultural (hoje Instituto de Patrimônio Histórico e Artístico Nacional IPHAN) providenciou o tombamento ao nível federal, inscrevendo-o sob o $\mathrm{n}$. 532, no Livro do Tombo Histórico e, posteriormente, disciplinando tal regime através da Portaria / IPHAN n. 314, de 14 de outubro de 1992. A própria Lei Orgânica do Distrito Federal consagrou, em seguida, a proteção e preservação desse patrimônio e ressaltou a importância da observação do tombamento em diversas de suas normas, considerando-o espaço especialmente protegido, como se extrai dos dispositivos seguintes: art. 247,.§ $2^{\circ}$; art. 295; art. 312, inciso VI; art. 314, parágrafo único, inciso IV.

Não obstante a relevância do ponto, apenas os Desembargadores Nívio, Dácio Vieira e Edson Smaniotto(70) fizeram referência em seus votos a esse aspecto, deixando de merecer apreciação por parte dos outros julgadores, apesar de dizer respeito a bem fundamental e direito humano, se relacionado diretamente com a qualidade de vida.

\subsubsection{A Defesa pelo Ministério Público dos bens jurídicos envolvidos}

O Ministério Público brasileiro, desde a edição da Lei da Política Nacional do Meio Ambiente (Lei n. 6.938, de 31 de agosto de 1981), possui legitimidade para a defesa do Meio Ambiente, não só na esfera criminal, mas também na cível (art. 14, $\S 1^{\circ}$ ). Com a Lei n. 7.347, de 24 de julho de 1985, que disciplinou a defesa de outros bens jurídicos de natureza transindividual como os direitos do consumidor (art. $1^{\circ}$ ), entre outros, pela ação de cunho coletivo denominada ação civil pública (assemelhada às class actions americanas, mas com traços próprios), o Parquet passou a dispor de instrumentos eficazes para cumprir o seu mister. Entre eles, acham-se o inquérito civil (art. $8^{\circ}, \S 1^{\circ}$ ), para efetuar a investigação, e o ajustamento de conduta, com força de título executivo extrajudicial, pelo qual os responsáveis se obrigam a reparar os danos causados (art. $5^{\circ}, \S 6^{\circ}$ ).

(70) Às páginas 31-32, 56, 82, 88, 93-94, respectivamente, do acórdão em exame. 
Finalmente, com a Constituição Federal de 5 de outubro de 1988 sacramentou-se, definitivamente, como atribuição institucional do Ministério Público, a defesa dos chamados direitos ou interesses metaindividuais. O art. 129, inciso III da Carta, prescreveu-Ihe tal função constitucional e exemplificou o objeto de tutela com o próprio meio ambiente, admitindo a proteção de outros bens em cláusula aberta, a saber: "outros bens difusos e coletivos". O Código de Defesa do Consumidor - CDC - (Lei n. 8.078, de 11 de setembro de 1990), trouxe os parâmetros conceituais de interesses difusos, coletivos e individuais homogêneos em seu art. $81^{(71)}$. Tais direitos e interesses são inegavelmente qualificados como direitos humanos e fundamentais ${ }^{(72)}$.

No caso do MPDFT, a Lei Complementar n. 75, de 20 de maio de 1993, que dispõe sobre o Ministério Público da União, veio a reiterar tais atribuições e conceder-Ihe a possibilidade de expedir recomendações (art.6 , inciso $\mathrm{XX}$ ) para o exercício dessa função. Logo, não se discute a respeito da sua legitimidade para agir no caso em epígrafe. Os bens tutelados (saúde e ambiente) amoldam-se perfeitamente na definição de interesses difusos dada pelo art. 81 do $C D C$, de modo que não mereceu repulsa do TJDFT o exercício dessa função constitucional do Ministério Público no caso em consideração.

\subsubsection{Veredicto final}

Após debates que renderam 104 páginas de acórdão proferido pelo Conselho Especial, o Tribunal de Justiça do Distrito Federal e Territórios decidiu pela competência do Distrito Federal em disciplinar aspectos referentes à proteção do Meio-Ambiente e saúde pública na implantação e funcionamento das ERBs e pela impossibilidade de remoção das estações instaladas com licenciamento, de acordo com a lei vigente à época e a remoção daquelas que se constituíram sem autorização.

Da decisão a Global Village Telecom LTDA. - GVT (uma das associadas da $A C E L$ ) interpôs recurso ordinário, que até o término desse trabalho estava sendo processado.

(71) Diz o citado dispositivo: "Art. 81. A defesa dos interesses e direitos dos consumidores e das vítimas será ser exercida em juizo individualmente, ou a título coletivo. Parágrafo único. A defesa coletiva será exercida quando se tratar de: 1 -interesses ou direitos difusos, assim entendidos, para efeitos deste código, os transindividuais, de natureza indivisivel, de que sejam titulares pessoas indeterminadas e ligadas por circunstâncias de fato; 11 - interesses ou direitos coletivos, assim entendidos, para efeitos deste código, os transindividuais, de natureza indivisível de que seja titular grupo, categoria ou classe de pessoas ligadas entre si ou com a parte contrária por uma relação jurídica base; III - interesses ou direitos individuais homogêneos, assim entendidos os decorrentes de origem comum."

(72) A esse respeito, veja BATISTA, Roberto Carlos. Coisa julgada nas ações civis públicas: direitos humanos e garantismo. Rio de Janeiro: Lumen Juris, 2005, p. 41-94. 


\section{CONCLUSÓES}

Após essa abordagem ligeira sobre assunto tão atual e tão desafiador, pela complexidade e gravidade, que são os riscos sanitário-ambientais da exposição humana a campos eletromagnéticos, pode-se chegar às seguintes conclusões:

1) Os arrojos da tecnologia congrega facilidades, inovações fascinantes e de grande utilidade, como é o caso da telefonia celular, mas, ao mesmo tempo impõe uma insegurança muito grande em relação à proteção de bens e valores fundamentais, como a saúde, o meio ambiente e a qualidade de vida.

2) Estudos científicos desenvolvidos em diversos países demonstram que, embora não haja dados inequívocos de que a exposição humana a campos eletromagnéticos seja prejudicial à saúde, há fortes indícios, em pesquisas já desenvolvidas em diversos países, que apontam uma correlação muito evidente entre a mencionada exposição (a que são submetidos os usuários de telefonia celular e os vizinhos de ERBs) e 0 efeitos prejudiciais e graves em relação à saúde.

3) Inúmeros países europeus já estabeleceram medidas de proteção, no âmbito de políticas públicas e na esfera legislativa, para acautelar males à saúde e ao ambiente decorrente da exposição a campos eletromagnéticos, em especial, no caso da telefonia móvel, adotando o princípio da precaução.

4) A França admitiu, oficialmente, para o caso do uso de telefonia celular, o princípio da precaução; mas, de forma inovadora, concebeu o princípio da atenção para a circunstância de funcionamento das ERBs.

5) O Brasil, através de política pública recém-elaborada, consagrou o princípio da precaução para o caso da telefonia celular (aí compreendidas as ERBs), embora o princípio já estivesse previsto no ordenamento constitucional vigente.

6) O Poder Judiciário brasileiro ainda não vem admitindo como fundamento o mencionado princípio, haja visto o caso estudado na capital federal.

7) No caso de ERBs a poluição eletromagnética ameaça direitos difusos de natureza fundamental e humana, a saber: a saúde pública e o ambiente. Logo, inarredável se mostra a aplicação do princípio da precaução(73).

(73) Em seminário ocorrido em Sāo Paulo em 2004, organizado pela Escola Superior do Ministério Público daquele Estado, vários dos expositores de formações diversas, igualmente, se pronunciaram no sentido da necessidade de se aplicar o princípio da precaução no caso em estudo: SALLES, A. A. de; FERNÁNDEZ, C. R. O impacto das radiações não-ionizantes, da telefonia móvel e o princípio da precaução; 


\section{REFERENCIAS}

AFOM. Liens \& Documents.Les réssources sur la "santé" en français. Document(s) de référence. Disponivel em: <http:www.afom.fr/v3/FILE_DOWNLOAD.php? doc_ID $=279 \&$ mode $=$ directopen $>$. Acesso em 19.07.06

Association Française des Operateurs Mobiles (AFOM), Liens \& Documents. Les ressources sur la "santé" en français Disponível em: <http://www.afom.fr/ v3/TEMPLATES/liens_documents_11.php?rubrique_ID=8 "

BATISTA, Roberto Carlos. Coisa julgada nas ações civis públicas: direitos humanos e garantismo. Rio de Janeiro: Lumen Juris, 2005, 296 p.

BECK, Ulrich. La societé du risqué: sur la voie d'une autre modernité. Trad. Laure Bernardi. Paris: Flammarion, 2003, 521p.

BESANCENOT, Jean-Pierre. Le principe de précaution devant les risques sanitaires. In LARCENEUX, André; BOUTELET, Marguerite (Dir.). Le principe de précaution: débats et enjeux. Dijon: Editions Universitaires de Dijon, 2005, p. 47-67 (Collection Sociétés).

BRÜLLER, Gisele Borghi; FIGUEIREDO, Guilherme José Purvin. O direito ambiental face à telefonia móvel: aplicação concreta do princípio da precaução. In Escola Superior do Ministério Público de São Paulo; Imprensa Oficial Estado de São Paulo. Poluição eletromagnética: saúde pública, meio ambiente, consumidor, cidadania: impacto das radiações das antenas e dos aparelhos celulares. Caderno Jur. SP, v. 6, n. 2, abr.jun. 2004, p. 259-269.

CARLO, George; SCHRAM, Martin. Téléphones portables: oui, ils sont dangereux: révelations d'un scientifique. Paris: Editions Carnot, 2001, 185p.

CICOLELLA, André; BROWAEYS, Dorothé Benoit. Alertes santé. Paris: Fayard, 2005.

DI PIETRO, Maria Sylvia Zanella. Direito administrativo. 15. ed. São Paulo: Atlas, 2003.

DODE, Adalgiza Condessa; LEÃO, Mônica Maria Diniz. Poluição ambiental e exposição humana a campos eletromagnéticos: ênfase nas estações rádios-base-base de telefonia celular; MARCHESAN, Ana Maria Moreira. A estações de rádios-base-base de telefonia celular no contexto de uma sociedade de riscos. TEJO, Francisco de Assis. Impacto dos campos eletromagnéticos ambientais sobre a saúde e a necessidade de adotar-se o princípio da precaução. DRUMOND, Ivens; FRANCO NETTO, Guilherme; FENNER, André. CEM- Campos eletromagnéticos: aspectos legais sobre a saúde: perspectivas e sugestões. BRÜLLER, Gisele Borghi; FIGUEIREDO, Guilherme José Purvin. O direito ambiental face à telefonia móvel: aplicação concreta do princípio da precaução. In: Escola Superior do Ministério Público de São Paulo; Imprensa Oficial Estado de São Paulo. Poluição eletromagnética: saúde pública, meio ambiente, consumidor, cidadania: impacto das radiações das antenas e dos aparelhos celulares. Caderno Jur. SP, v. 6, n. 2, abr./ jun. 2004). No mesmo sentido DELHOSTE, quando diz: "L'exposition humaine aux radiofréquences apparait ainsi comme le cas exemplaire et incontournable d'application du principe de précaution " (DELHOSTE, Marie-France. Radiotéléphonie mobile et principe de précaution: la surprenante position du Conseil d'Etat. In: Expentise des système d'information, mars. 2003, p.101). 
DELHOSTE, Marie-France. Radiotéléphonie mobile et principe de précaution: la surprenante position du Conseil d'État. In: Expertise des système d'information, mars. 2003, p. 96-101.

DODE, Adalgiza Condessa; LEÃO, Mônica Maria Diniz. Polvição ambiental e exposição humana a campos eletromagnéticos: ênfase nas estações rádio-base de telefonia celular. Poluição eletromagnética: saúde pública, meio ambiente, consumidor, cidadania: impacto das radiações das antenas e dos aparelhos celulares. Caderno Jur. SP, v. 6, n. 2, p. 121-139, abr./ jun. 2004.

DRUMOND, Ivens; FRANCO NETTO, Guilherme; FERMMER. André.CEM: Campos eletromagnéticos: aspectos legais e impactos sobre a saúde: perspectivas e sugestões. In: Escola Superior do Ministério Público de São Paulo ; Imprensa Oficial Estado de São Paulo. Poluição eletromagnética: saúde pública, meio ambiente, consumidor, cidadania: impacto das radiações das antenas e dos aparelhos celulares. Caderno Jur. SP, v. 6, n. 2, p. 229-244, abr./ jun. 2004.

GAUGIER, R. et al. Votre GSM, votre santé: on vous ment !:150 pages pour rétablir la vérité : livre blanc des incidences du téléphone mobile et des antennes relais sur votre santé. Paris: Marco Pietter Editeur, 2003. 141 p. (Collection Résurgence).

GODARD, Olivier et al.Traité des nouveaux risques.Paris: Gallimard, 2002, $620 \mathrm{p}$.

GOSSEMENT, Arnaud. Le principe de précaution: essai sur l'incidence de l'incertitude scientifique sur la décision et la responsabilité publiques. Paris: L'Harmattan, 2003, 527 p [ Coll. Logiques juridiques].

GROSSIEUX, Patrick. Principe de précaution et sécurité sanitaire. Aix-enProvence: Presses Universitaires d'Aix-Marseille, 2003, 565p.

GUÉNEL, Pascal et al. Rayonnement non ionisants. In GUERIN, Michel et al. Environnement et santé publique : fondements et pratiques. Canadá: Éditions TEC \& DOC/Edisem, 2003. p. 441-462.

HERMITTE, Marie Angèle. Os fundamentos jurídicos da sociedade do risco: uma análise de U. Beck. In VARELLA, Marcelo (Org.). Governo dos riscos. Brasília. Rede Latino-Americana-Européia sobre Governo dos Riscos, 2005. p. 11-40.

DORMONT, Dominique. Proposition pur le principe de la précaution à la lumière de l'affaire de la vache folle. In: KOURILSKY, Philippe ; VINEY, Geneviève. Le principe de précaution. Paris: La Documentation Française, 2000. $405 \mathrm{p}$.

KOSTREZEWSKI-PUGNAT, Valérie.Téléphoie mobile, environnement et santé: bilan d'une coexistence sous le conrole du juge. In: JCP - La Semaine Juridique Adminstration et Collectivités territoriales, n. 23, juin. 2003, p. 729-738). 
KOURILSKY, Philipe; VINEY, Geneviève. Rapport au Premier ministre: le principe de précaution. Paris: Editions Odile Jacob/La Documentation Française, 2000, $405 \mathrm{p}$.

LAGADEC, Patrick. La civilisation du risque: catastrophes technologiques et responsabilité sociale. Paris: Seuil, 1981 [ Collection "Science ouverture".

LENTIN, Jean-Pierre. Ce sondes qui tuent, ces ondes qui soignent: téléphones portables, ordinateurs, micro-ondes, électricité, magnétisme: quels dangers pour notre santé? Paris: Albin Michel, 2004, 340 p.

MARCHESAN, Ana Maria Moreira. As estações rádio-base de telefonia celular no contexto de uma sociedade de risco. In Escola Superior do Ministério Público de São Paulo; Imprensa Oficial Estado de São Paulo. Poluição eletromagnética: saúde pública, meio ambiente, consumidor, cidadania: impacto das radiações das antenas e dos aparelhos celulares. Caderno Jur. SP, v. 6, n. 2, p.141-155, abr./ jun. 2004.

MASCHI, J.-Pierre.Combat pour un e idée: la pollution électromagnétique, Paris: France Europe Editions, 2005, 549 p.

MATTOS, Inês; kOIFMAN, Sérgio. Campos eletromagnéticos e câncer: contribuição das ciências biológicas. Poluição eletromagnética: saúde pública, meio ambiente, consumidor, cidadania: impacto das radiações das antenas e dos aparelhos celulares. Caderno Jur. SP, v. 6, n. 2, p.75-98, abr./ jun. 2004.

MINISTÈRE DE L'EMPLOI ET DE LA SOLIDARITÉ, DIRECTION GÉNÉRALE DE LA SANTÉ. Les téléphones mobiles, leurs stations de base et la santé : état des connaissances et recommandations. Paris: 2001, La Documentation Française, 440p.

NAVIER, Zmirou. Risques émergents associes aux nouvelles technologies. Un cas d'ecole: les champs électromagnétiques associés à la téléphonie mobile. In: BORDILLON, François; BRÜCKER, Gilles; TABUTEAU, Didier. Traté de santé publique. Paris : 2004, Flamarion, p. 107-111 [Coll.MédicineSciences].

NOIVILLE, Christine.Ciência, decisão, ação: três observações em torno do princípio da precaução. In: VARELLA, Marcelo (Org.). Governo dos riscos. Brasília. Rede Latino-Americana-Européia sobre Governo dos Riscos, p. 56-80. 2005.

OMS. Bureau Régional pour l'Europe. Les champs életromagnétiques. Compenhague: OMS/Europe, 1999, 24 p. (Collection de brochures Collectivités locales, environnement et santé, n. 32).

SALLES , A. A. de; FERNÁNDEZ, C. C. O impacto das radiações não-ionizantes da telefonia móvel e o princípio da precaução. In Escola Superior do Ministério Público de São Paulo; Imprensa Oficial Estado de São Paulo. Poluição eletromagnética: saúde pública, meio ambiente, consumidor, cida- 
dania: impacto das radiações das antenas e dos aparelhos celulares. Caderno Jur. SP, v. 6, n. 2, p.17-46, abr./ jun. 2004.

SANTINI, Roger. Téléphone mobiles cellulaires et stations relais: le risque pour la santé: arguments scientifiques et conseils pratiques. Paris : Marco Pietter Editeur, 1998, 206 p (Collection Résurgence).

TEJO, Francisco de Assis Ferreira. Impacto dos campos eletromagnéticos ambientais sobre a saúde e a necessidade de adotar-se o princípio da precaução. In Escola Superior do Ministério Público de São Paulo; Imprensa Oficial Estado de São Paulo. Poluição eletromagnética: saúde pública, meio ambiente, consumidor, cidadania: impacto das radiações das antenas e dos aparelhos celulares. Caderno Jur. SP, v. 6, n. 2, p. 159-202, abr./ jun. 2004.

WHO.ELECTROMAGNETIC FIELDS (EMF). Disponivel em "http://www.who.int/ peh-emf/project/EMF_Project/en/index1.htm". Acesso em: 17.07.06. 